\title{
Sources of CAM3 temperature bias during northern winter from diagnostic study of the temperature bias equation
}

\author{
Lin-Lin Pan · Richard Grotjahn · Joe Tribbia
}

Received: 24 March 2009/ Accepted: 9 June 2009/Published online: 28 June 2009

(c) The Author(s) 2009. This article is published with open access at Springerlink.com

\begin{abstract}
The Community Atmosphere Model version 3 (CAM3) temperature simulation bias is examined in this paper. We compare CAM3 output with European Centre for Medium-Range Weather Forecasts (ECMWF) 40 year reanalysis (ERA-40) data. We formulate a time mean temperature bias equation then evaluate each term in the equation. Our focus is on the Northern Hemisphere winter time. We group the temperature equation terms into these categories: linear advection terms, nonlinear advection terms, transient eddy terms and diabatic heating, and find that linear advection and diabatic bias are the largest. The nonlinear terms (velocity bias advection of temperature bias) are much smaller than each of the other groups of terms at all levels except near the surface. Linear advection terms have dipolar pattern in the Atlantic (negative NW of positive) which reflects the shift of the CAM3 model North Atlantic storm track (NAST) into Europe, especially in the upper troposphere; opposite sign dipolar structure occurs over Alaska (positive) and the north Pacific storm track (negative). The transient advection terms in middle latitudes are larger in the upper troposphere and generally positive along the Atlantic storm track. Along the north Pacific storm track (NPST), the transient terms are negative in the mid and lower troposphere over much of the NPST (positive in upper troposphere). The diabatic heating bias has large values in the tropics along the Intertropical Convergence Zone (ICZ) and along the midlatitude storm
\end{abstract}

L.-L. Pan $(\varangle) \cdot$ R. Grotjahn

Department of Land, Air and Water Resources,

University of California, Davis, CA 95616, USA

e-mail: 1lpan@ucdavis.edu

J. Tribbia

National Center for Atmospheric Research, Boulder, CO, USA tracks. During this time of year the ICZ is mainly in the Southern Hemisphere, but CAM3 emphasizes an ICZ-like heating in the northern hemisphere of the Atlantic and Pacific Oceans. CAM3 tends to have a weaker ICZ, especially in the Atlantic. In midlatitudes, we find large bias in heating by precipitation and vertically averaged net radiation over the NAST, Europe, and the Middle East.

Keywords CAM3 - Temperature bias - Diabatic heating · Northern hemisphere storm tracks $\cdot$ Arctic

\section{Introduction}

Global climate system models are used to simulate past, present and future climate. The Community Climate System Model version 3 (CCSM3; Collins et al. 2004, 2006a, b; Hurrell et al. 2006) is such a climate model developed at National Center for Atmospheric Research (NCAR). Community Atmosphere Model version 3 (CAM3) is the atmospheric part of CCSM3. CAM3 was developed from previous versions (Kiehl et al. 1998a, b), and has many improvements to the parameterized physics packages. Several improvements were made in the representation of cloud and precipitation processes (Boville et al. 2006), which include separation of liquid and frozen precipitation, and different treatments of liquid and ice condensate; advection, detrainment, and sedimentation of cloud condensate. The improvements in treatments of aerosols include stratospheric volcanic aerosols, a prescribed distribution of sulfate, soil dust, carbonaceous species, and sea salt, and the option of prognostic sulfur cycle (e.g., Rasch et al. 2006). The improvements in parameterizations of radiation include new parameterizations for the longwave and shortwave interactions with water vapor, and a 
generalized treatment of cloud geometrical overlap (e.g., Briegleb and Bromwich 1998a, b). The dynamical cores of CAM3 include the spectral core; the semi-Lagrangian core (Williamson and Olson 1994); and the finite volume core (Lin 2004). The spectral core is used for this study. Sensitivity studies tell us that the dominant features (e.g., pattern of temperature field) are similar when different schemes are used. For details of the physics and dynamics of CAM3 the reader is referred to Collins et al. (2004, 2006b).

Compared with observed climate fields (e.g., sea level pressure, wind), simulation bias (error) still exists in CAM3, though many improvements have been made upon earlier versions of the model. Hurrell et al. (2006) found higher than observed sea level pressure (SLP) in the subtropics and lower than observed SLP in polar and subpolar latitudes during both winter and summer. They also show that easterly trade winds and low-latitude surface wind stress are too strong in CAM3 simulations. Also, a westerly bias in the middle latitude winds exists in both hemispheres throughout the year. Further study revealed that the simulation errors in winds, pressure fields and the transient momentum fluxes are related to each other (e.g., Hurrell et al. 2006).

Simulation bias may vary with model resolutions. The horizontal resolutions $\mathrm{T} 42$ and $\mathrm{T} 85$ are often used in CAM3 simulations, and several studies (e.g., Hack et al. 2006a) have investigated the differences in the simulation results between these two horizontal spectral truncations. DeWeaver and Bitz (2006) showed that the simulation of Arctic sea ice, air temperature and hydrology in some regions are improved in the higher-resolution atmosphere. On the other hand, the boreal winter warm bias at high latitudes is stronger in the T85 simulation than that at lower resolution throughout troposphere (Hack et al. 2006a). Therefore, Hack et al. (2006a) conclude that the high-resolution version of the CAM3, especially the coupled model (CCSM3) has uneven improvement. Thus the simulation bias of the model cannot be solved by using a higherresolution. In particular, higher-resolution still does not solve the simulation problems in the position and strength of the Beaufort high, surface wind and sea ice thickness in the Arctic region. Consequently, this report shall further examine the source of simulation bias in CAM3, with focus on the middle and high latitudes (e.g., Arctic region). In addition, some results from the tropics shall also be shown.

We shall investigate the forcing field associated with model-simulated temperature bias and study the contribution of each term to the simulated bias of CAM3 by parsing the temperature equation. The model bias is defined by subtracting the observed value from the model-simulated value for that variable then averaging over a suitable time (e.g., a seasonal average).
The outline of the paper is as follows: The primary diagnostic, the temperature bias equation used in this study is briefly derived in the next section. Bias in the diabatic field at various levels is discussed in Sect. 3. Also in Sect. 3, a proxy variable is used to identify the $\mathrm{NH}$ storm tracks because some terms in the temperature bias equation are often large along those tracks. The contributions by surface sensible heat flux, precipitation, and net radiation to the vertically integrated diabatic heating bias are discussed in Sect. 4. Analyses of the bias in temperature from linear terms, nonlinear terms, and transient contributions to the time mean are given in Sect. 5 . The link between precipitation bias near the western European coast and sea level pressure in the Arctic is briefly explored in Sect. 6. The paper concludes with a summary discussion.

\section{Method used in diagnostic study}

Bias of any variable refers to: model data minus corresponding observational data averaged over time. A primary diagnostic used here is the temperature bias equation. The equation is formed by evaluating the time mean temperature equation using model data and then subtracting the same equation constructed using observational data.

The CAM3 data used here are obtained by running a 20 year atmospheric model intercomparison project (AMIP) type simulation from 1979 to 1998 . The model was run with 26 levels in the vertical and horizontal resolution truncated triangularly at 42 wavenumbers (T42). CAM3 output was saved four times daily. Only the Northern Hemisphere winter months: December, January, and February are studied here.

The observational data used here are European Centre for Medium-Range Weather Forecasts (ECMWF) 40 year reanalysis, ERA-40 (Uppala et al. 2005). We use $4 \times$ daily ERA-40 data from 1979 to 1998 . The variables used here include zonal wind, meridional wind, temperature, and vertical velocity in $p$ coordinate.

The temperature $(T)$ equation in pressure $(p)$ coordinates is:

$\frac{\partial T}{\partial t}+\vec{V} \cdot \nabla T+\omega\left(\frac{\partial T}{\partial p}-\frac{\alpha}{C_{p}}\right)=Q$,

where $\vec{V}, \omega, \alpha, C_{p}$, and $Q$ denote wind velocity, vertical velocity in $p$ coordinates, specific volume, specific heat at constant pressure, and diabatic heating, respectively. We evaluate the thermodynamic energy equation in pressure coordinates since ERA-40 and CAM data are available at many such levels. We define time averaging with an overbar and use a prime for the deviation from that average. Subscript "C" denotes CAM3 data; subscript "E" denotes ERA-40 data. Using the time mean of the CAM3 model output, Eq. 1 becomes: 


$$
\begin{aligned}
\bar{V}_{\mathrm{C}} & \cdot \nabla \bar{T}_{\mathrm{C}}+\bar{\omega}_{\mathrm{C}}\left(\frac{\partial \bar{T}_{\mathrm{C}}}{\partial p}-\frac{\alpha_{\mathrm{C}}}{C_{p}}\right) \\
= & -\overline{V_{\mathrm{C}}^{\prime} \cdot \nabla T_{\mathrm{C}}^{\prime}}-\overline{\omega_{\mathrm{C}}^{\prime} \frac{\partial T_{\mathrm{C}}^{\prime}}{\partial p}}+\bar{Q}_{\mathrm{C}} .
\end{aligned}
$$

The time mean of Eq. 1 using ERA-40 data becomes:

$$
\begin{aligned}
\bar{V}_{\mathrm{E}} & \cdot \nabla \bar{T}_{\mathrm{E}}+\bar{\omega}_{\mathrm{E}}\left(\frac{\partial \bar{T}_{\mathrm{E}}}{\partial p}-\frac{\alpha_{\mathrm{E}}}{C_{p}}\right) \\
= & -\overline{V_{\mathrm{E}}^{\prime} \cdot \nabla T_{\mathrm{E}}^{\prime}}-\omega_{\mathrm{E}}^{\prime} \frac{\partial T_{\mathrm{E}}^{\prime}}{\partial p}+\bar{Q}_{\mathrm{E}} .
\end{aligned}
$$

We define a $\wedge$ notation for the bias, for example: $\bar{T}_{\mathrm{C}}-\bar{T}_{\mathrm{E}}=\hat{T}$. Subtracting $\quad$ Eqs. $2-3$ yields our primary diagnostic, the temperature bias equation:

$$
\begin{gathered}
\underbrace{\hat{V} \cdot \nabla \bar{T}_{\mathrm{E}}+\bar{V}_{\mathrm{E}} \cdot \nabla \hat{T}+\hat{\omega}\left(\frac{\partial \bar{T}_{\mathrm{E}}}{\partial p}-\frac{\alpha_{\mathrm{E}}}{C_{p}}\right)+\bar{\omega}_{\mathrm{E}}\left(\frac{\partial \hat{T}}{\partial p}-\frac{\hat{\alpha}}{C_{p}}\right)}_{\text {Linear Group }} \\
=\underbrace{-\hat{V} \cdot \nabla \hat{T}-\hat{\omega}\left(\frac{\partial \hat{T}}{\partial p}-\frac{\hat{\alpha}}{C_{p}}\right)}_{\text {Nonlinear Group }} \\
\underbrace{-\overline{V_{\mathrm{C}}^{\prime} \cdot \nabla T_{\mathrm{C}}^{\prime}}+\overline{V_{\mathrm{E}}^{\prime} \cdot \nabla T_{\mathrm{E}}^{\prime}}-\omega_{\mathrm{C}}^{\prime} \frac{\partial T_{\mathrm{C}}^{\prime}}{\partial p}+\overline{\omega_{\mathrm{E}}^{\prime} \frac{\partial T_{\mathrm{E}}^{\prime}}{\partial p}}}_{\text {Transient Group }}+\hat{Q}
\end{gathered}
$$

The terms at the left hand side are all terms that are linear in the bias; the aggregate of these terms is referred to as the Linear Group. The terms in the Linear Group are similar to a linear stationary wave model (hereafter, LSW) such as the model described in Branstator (1990) (see also Pan et al. 2006; Pan and Li 2008). A secondary goal of this paper is to show that the temperature equation part of the LSW would be valid for studying the CAM3 bias. However, assessing whether the other parts of the LSW could be used to study the bias is outside the scope of this paper. The first two terms on the right hand side (labeled Nonlinear Group) are all nonlinear combinations of the bias. The group of terms labeled Transient Group has the time mean contributions to the bias by transient heat advection. Finally, $\hat{Q}$ is the bias in diabatic heating.

The CAM3 and ERA-40 diabatic heating are each calculated as a residual from a potential temperature equation (Hoskins et al. 1989):

$$
\begin{aligned}
\bar{Q}= & \overline{\vec{V}} \cdot \nabla \bar{T}+\left(p / p_{0}\right)^{\frac{R}{C_{p}}} \bar{\omega} \partial \bar{\theta} / \partial p \\
& +\left(p / p_{0}\right)\left[\nabla \cdot \overrightarrow{\vec{V}}^{\prime} \theta^{\prime}+\partial \overline{\left(\omega^{\prime} \theta^{\prime}\right)} / \partial p\right],
\end{aligned}
$$

where $R$, and $\theta$ are the gas constant for dry air and potential temperature, respectively. $p_{0}$ is a reference pressure $(1,000 \mathrm{hPa})$. The relationship $\left(p / p_{0}\right)^{\frac{R}{C_{p}}} \partial \bar{\theta} / \partial p=\partial T / \partial p-$ $\alpha / C_{p}$ is used. In practice the $\theta$ form, Eq. 5 has smaller calculation error than a corresponding formulation using $\partial T / \partial p-\alpha / C_{p}$.

\section{Bias in diabatic heating fields}

The long term means of wind, temperature, vertical velocity and potential temperature were used in Eq. 5 to obtain diabatic heating in the CAM3 and ERA-40 data. Figure 1 shows the diabatic heating fields and bias at $\sigma\left(\frac{p}{p_{s}}\right)=0.3 \quad$ (Fig. 1a-c), $0.5 \quad$ (Fig. 1d-f), and 0.85 (Fig. 1g-i). Both ERA-40 and CAM3 simulation data have large diabatic heating mainly along the ICZ and Northern Hemisphere storm tracks. The diabatic heating fields are consistent with other published work (e.g., DeWeaver and Bitz 2004). The diabatic heating is consistent between levels and broadly similar between CAM3 and ERA-40. Differences (biases) are mainly associated with the ICZ and the Northern Hemisphere storm tracks.

The CAM3 and ERA-40 diabatic heating fields have large and interesting differences in the tropics. In the upper troposphere (Fig. 1a-c) the bias is strongly negative over the oceanic ICZ of the Atlantic, Indian, and western Pacific Oceans. Over Africa, northern Australia, and the northern Indian Ocean the bias is positive. The pattern is similar and stronger in the middle troposphere (Fig. 1d-f) but less strong in the lower troposphere. At $\sigma=0.85$ (Fig. 1g-i) the heating over the tropical continents is much less while the cooling over the tropical and subtropical oceans is strengthened; though the bias is smaller than other levels. This bias along the ICZ is consistent with the precipitation bias as indicated by satellite estimates along the equator (e.g., Hack et al. 1998; Hurrell et al. 2006). Often, such elongated dipolar bias structures are indicative of a shift in the location of a maximum and that is the case over the Indian Ocean (CAM3 has the ICZ much too far north). However, a similar elongated dipolar bias in the western Pacific is not due to a shift of the ICZ so much as CAM3 emphasizes the northern ICZ while ERA-40 emphasizes a parallel southern ICZ (commonly referred to as the equatorial part of the South Pacific Convergence Zone, SPCZ; Vincent 1994). The Atlantic ICZ is largely missing in CAM3 at all levels, a result that differs from ERA-40 much like the NCEP/DOE AMIP-II reanalysis (Kanamitsu et al. 2002) differs from ERA-40 (see discussion in Grotjahn 2008). While the Atlantic ICZ is missing in CAM3, ICZlike heating in the far eastern Pacific is stronger (and opposite sign at mid and upper levels) in CAM3 than in ERA-40.

In the Northern Hemisphere middle latitudes the stronger diabatic heating is associated with the two oceanic storm tracks. A proxy measure of the midlatitude storm tracks is band passed (2-8 days passed) transient heat transport $\left(\mathrm{v}^{\prime} \mathrm{T}^{\prime}\right)$. The maximum centers in the Pacific and Atlantic (Fig. 2) gives the position of the Pacific and Atlantic storm track. The NAST (North Atlantic storm track) is narrower in 
latitude and the bias shows the narrowness is due to much less heat flux over northern North America. The NAST is more zonal in CAM3 and extends into western Europe (instead of further north) leading to a dipolar bias, with stronger positive west of France. The zonal wind bias (Hurrell et al. 2006) has similar pattern as the heat fluxes; the subtropical jet across the north Atlantic is stronger, narrower, and more zonally elongated in CAM3. The NPST (North Pacific storm track) extends further across the Pacific and is also latitudinally narrower in CAM3. The bias field along the NPST shows weaker heat flux at the start and a dipolar pattern (reversed from the NAST) where the heat flux is stronger much further downstream and to the north. The zonal wind bias again finds a stronger subtropical jet stream across the north Pacific in CAM3.

The NAST has positive heating in middle and lower tropospheric levels of both ERA-40 (Fig. 1d, g) and CAM3 (Fig. 1e, h). At these levels CAM3 has stronger heating along the middle and downstream end of the NAST leading to positive bias there. In contrast, the upper level bias is negative over the upstream half of the NAST. The opposite is true for the NPST off the east coast of Asia: low level diabatic heating bias is strongly negative along the initial portion of the NPST.

The horizontal plots in Fig. 1 primarily give the geographic distribution of the heating and bias. They also give some indication of the vertical structure of the diabatic heating and its bias. However, longitudinal cross sections of average values within carefully chosen latitude bands are more effective for showing the vertical structure. Figure $3 \mathrm{a}-\mathrm{c}$ show longitudinal cross sections of heating and bias over the longitudinal belt from $10^{\circ} \mathrm{S}$ to the equator, roughly along the bands of mid and upper level negative diabatic heating bias seen in Fig 1c, f. The diabatic heating in ERA-40 (Fig. 3a) generally reaches peak values in midtroposphere as does CAM3 (Fig. 3b). The models have similar vertical structure for the heating (comparing Fig. 3a, b). Consequently, the bias has largest values in the middle and upper troposphere for this longitudinal belt.

Cross sections along a second longitudinal belt, $0^{\circ}-10^{\circ} \mathrm{N}$, are shown in Fig. 3d-f. This belt lines up some positive bias regions in the Pacific and Indian Oceans as well as over Africa. It is seen that over the western Pacific and Indian Oceans the bias is positive mainly in the middle troposphere, which indicates CAM3 has stronger diabatic heating at those places. Notable positive heating over each of the oceans at low levels found in ERA-40 is picked up closely by CAM3.

A set of longitudinal cross sections shown in Fig. $3 \mathrm{~g}-\mathrm{i}$ indicate how the heating and bias are distributed along the NPST as well as for the NAST start, where the bias tends to be larger. Figure $3 \mathrm{j}-1$ show the next $10^{\circ}$ longitudinal band north and are intended to display more of the NAST where the bias is larger. In ERA-40 the diabatic heating becomes
Fig. 1 a-c Diabatic heating at $\sigma=0.3$ derived as a residual using a ERA-40 and b CAM3 data. The bias is shown in (c). The contour interval is $10^{-5} \mathrm{~K} \mathrm{~s}^{-1}$. Dashed contours used for negative values. d-f Similar to a-c, except at $\sigma=0.5$. $\mathbf{g}-\mathbf{i}$ Similar to a-c, except at $\sigma=0.85$

deeper as one moves downstream in both the NPST (Fig. 3g) and NAST (Fig. 3j). CAM3 reproduces this deepening, though not as much, consequently the bias at upper levels is negative on the downstream end of the NAST. At the downstream end of the NAST at low levels the bias is positive (Fig. 3k) in large part because the CAM3 NAST is further south (Fig. 3h). So part of the bias along the NAST reflects the northeastward bending storm track in ERA-40 that is somewhat more zonal in CAM3. Low level diabatic cooling occurs over both continents in both CAM3 and ERA40 , though it is much larger in CAM3. The negative bias (excess cooling) over the northern continents is largely confined below $\sigma=0.85$ and is stronger over longitudes $60^{\circ}-120^{\circ} \mathrm{E}$, a region where CAM3 is known to have a very large positive bias in low level cloud amount. The excessive low cloudiness (and possibly excessive snow cover) in CAM3 (e.g., Vavrus and Waliser 2008) are consistent with CAM3 having more strongly negative net radiation. Over eastern North America CAM3 has low level cooling where ERA-40 has heating (Fig. 3j, k). Just east of both continents, CAM3 reproduces the low level heating over the ocean areas found in ERA-40. The excess diabatic heating by CAM3 along the NAST occurs first mainly at low levels $\left(75^{\circ}-50^{\circ} \mathrm{W}\right)$ then later along the NAST $\left(50^{\circ}-0^{\circ} \mathrm{W}\right)$ the bias is mainly in middle troposphere levels (Fig. 3i, 1). While the diabatic heating at middle levels is somewhat stronger in CAM3, the upper level heating is too weak in CAM3 along the NAST (Fig. 31). In contrast to the situation along the NAST, lower level heating is generally underestimated by CAM3 for the first half of the NPST. There is again positive bias in the middle troposphere on the downstream end of the storm track but it is much less for the NPST than it was for the NAST. The cooling bias in the upper troposphere is even stronger for the NPST than it was for the NAST. As in the tropical belts, the general sense is that the diabatic heating extends to higher elevations in ERA-40 than in CAM3 data.

Hurrell et al. (2006) found that the tropical precipitation is well simulated in CAM3. There is, however, a tendency for the tropical precipitation maxima to remain in the Northern Hemisphere throughout the year, while precipitation tends to be less than indicated by satellite estimates along the equator. During northern winter, the CAM3 simulates the observed maxima in precipitation associated with the convergence zones over the South Pacific, South America, and Africa, though rainfall rates over the latter region are higher than observed. These results are consistent with vertically integrated diabatic heating $\left(Q_{1}\right)$ and precipitation bias discussed later in this paper. The 

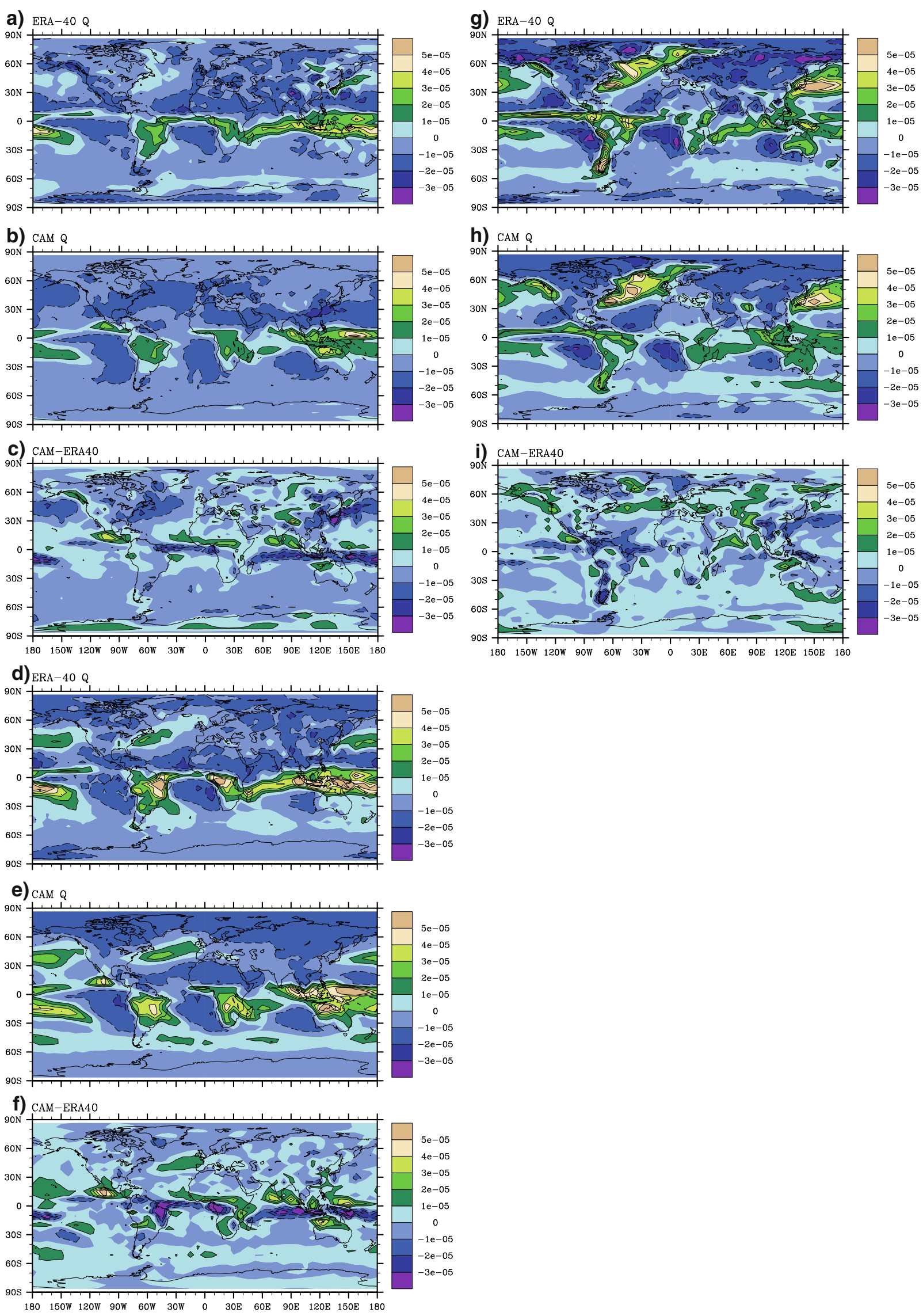

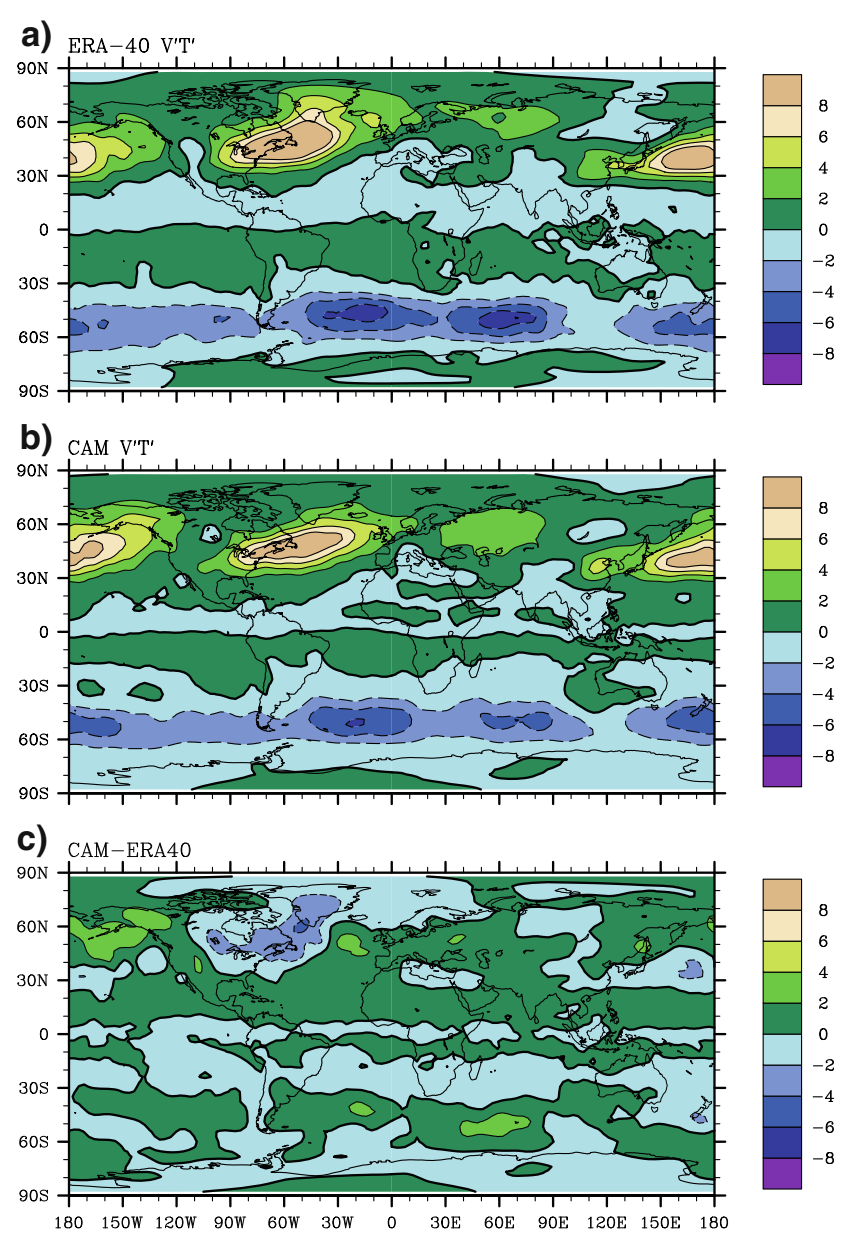

Fig. 2 Band passed (2-8 days) northward heat flux per unit mass during DJF at $\sigma=0.5$. a ERA-40, b CAM3, and $\mathbf{c}$ bias (CAM3ERA40). The contour interval is $2 \mathrm{~K} \mathrm{~ms}^{-1}$. Dashed contours used for negative values

simulation bias may depend slightly on the horizontal resolution, however, the dominant patterns of many variables (e.g., precipitation) in two horizontal spectral truncations tested: T42 and T85, are similar (e.g., Hack et al. 2006a; Rasch et al. 2006). Hack et al. (2006a) found that although the high-resolution model exhibits a number of desirable simulation improvements, the bias in precipitation and diabatic heating is similar to that discussed in this paper for the lower resolution model. Also, according to Rasch et al. (2006), the higher-resolution runs probably overestimate the variability and the spatial extent of that variability, which tends to be strongly correlated with regions of strong convection over land and oceans.

\section{Contributions of precipitation, net radiation, and sensible heat flux to diabatic heating bias}

The diabatic heating is calculated as a residual and as such it may accumulate inaccuracies in the individual terms in
Eq. 5. While Eq. 5 implicitly includes contributions from radiation, sensible heating, and latent heating released by precipitation, Trenberth and Smith (2009) recommend testing the residual calculation against directly measured boundary contributions: sensible heat flux at the earth's surface $(\mathrm{SH})$, precipitation multiplied by latent heat of vaporization (LP), and top of atmosphere net radiation $(R)$. The vertically integrated diabatic heating from Eq. 5 should equal the sum of SH, LP, and $R$.

Integrating Eq. 5 in vertical obtains:

$$
\begin{aligned}
& C_{p} \int_{0}^{p_{\mathrm{s}}}\left\{\Delta \bar{T} / \Delta t+\overline{\vec{V}} \cdot \Delta \bar{T}+\left(p / p_{0}\right)^{\frac{R}{C_{p}}} \bar{\omega} \partial \bar{\theta} / \partial p+\left(p / p_{0}\right)\right. \\
& \left.\quad \times\left[\nabla \cdot \overline{\vec{V}^{\prime} \theta^{\prime}}+\partial \overline{\left(\omega^{\prime} \theta^{\prime}\right)} / \partial p\right]\right\} \frac{d p}{g}=\bar{Q}_{1},
\end{aligned}
$$

and

$\bar{Q}_{1}=C_{p} \int \frac{\bar{Q}}{g} d p$,

which also equals

$\bar{Q}_{1}=R+\mathrm{SH}+\mathrm{LP}$,

The bias $\hat{Q}_{1}$ between CAM3 output $\left(\bar{Q}_{1 \mathrm{C}}\right)$ and ECMWF analysis $\left(\bar{Q}_{1 \mathrm{E}}\right)$ is

$\hat{Q}_{1}=R_{\mathrm{C}}+\mathrm{SH}_{\mathrm{C}}+\mathrm{LP}_{\mathrm{C}}-\left(R_{\mathrm{E}}+\mathrm{SH}_{\mathrm{E}}+\mathrm{LP}_{\mathrm{E}}\right)$.

Figure 4 compares $\bar{Q}_{1}$ calculated using Eqs. 7 and 8 for both CAM3 and ERA-40 and the bias using each equation. The agreement between Eqs. 7 and 8 for ERA-40 is judged sufficient for our purposes; the differences are nearly everywhere less than $45 \mathrm{~W} \mathrm{~m}^{-2}$ and much less most places, including the places emphasized in this report. Along the NPST and NAST the differences between using Eqs. 7 or 8 are $5-20 \%$ in ERA-40 data (Fig. $4 \mathrm{a}, \mathrm{d}$ ). The CAM3 values using Eqs. 7 or 8 (Fig. 4b, e) are not quite as consistent. Along the NPST and NAST the differences between Eqs. 7 and 8 are generally between 5 and 30\% in CAM3 data with one exception: the heating maximum along the North American west coast $\left(45^{\circ}-60^{\circ} \mathrm{N}\right)$ is 50 $60 \%$ larger in the vertically integrated heating Eq. 7 than the boundary heating Eq. 8 (Fig. 4b, e). Over the Arctic Ocean and adjacent landmasses (excluding Greenland) Eqs. 7 and 8 give very similar results for both CAM3 and ERA-40 ( $<15 \%$ difference). The results provide sufficient validation of our diagnostic analysis and imply that the broad patterns of heating calculated as a residual at individual levels are probably reasonable.

The vertically integrated atmospheric diabatic heating is concentrated along the ICZ, SPCZ, the Southern Hemisphere tropical land masses, and the Northern Hemisphere storm tracks (NPST and NAST) during DJF. Comparison 

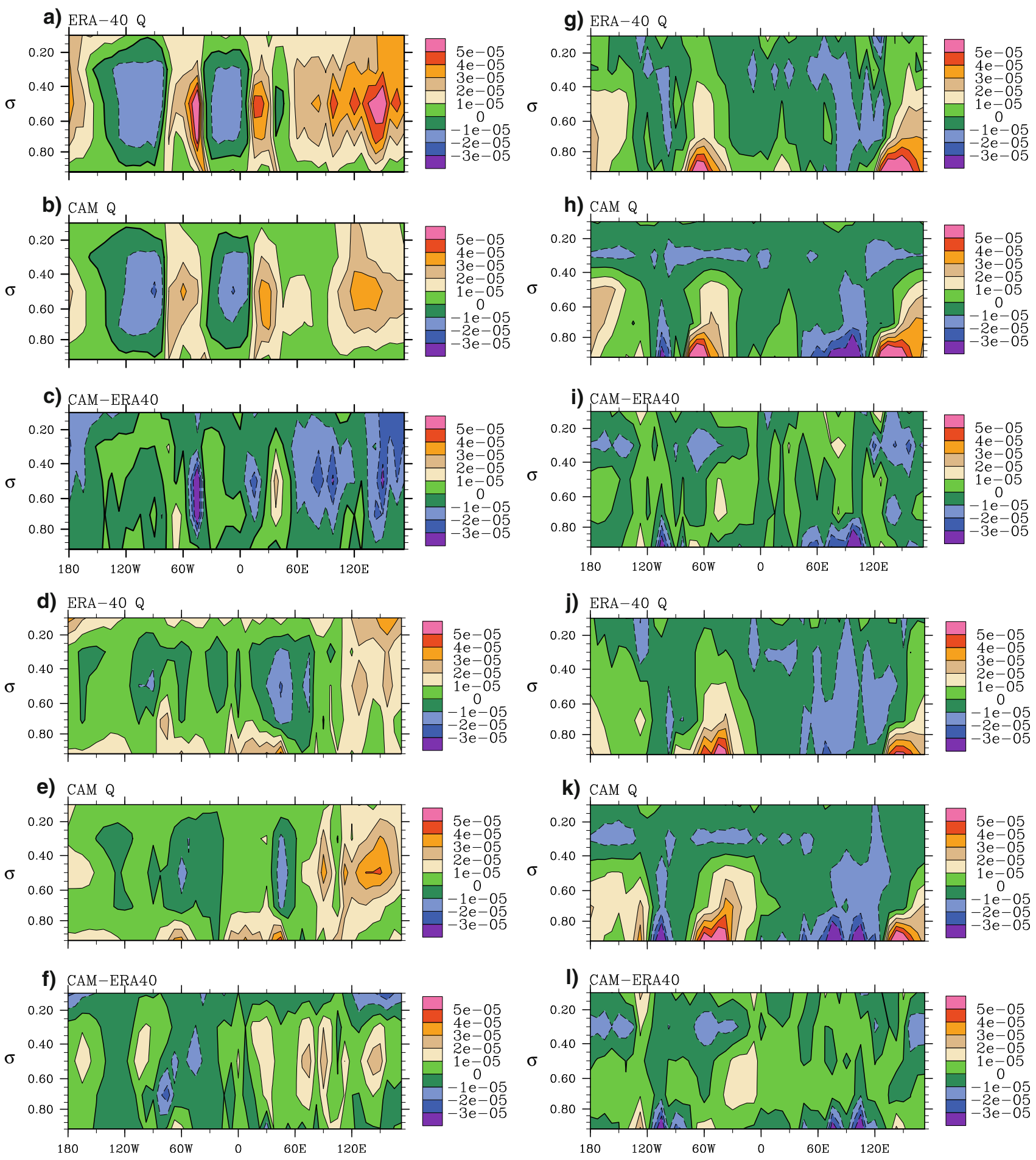

Fig. 3 a-c Longitudinal cross sections along $10^{\circ} \mathrm{S}-0^{\circ}$ for the diabatic heating derived as a residual using a ERA-40 and b CAM3 data. The bias is shown in (c). The contour interval is $10^{-5} \mathrm{~K} \mathrm{~s}^{-1}$. Dashed contours used for negative values. $\mathbf{d}-\mathbf{f}$ Similar to $\mathbf{a}-\mathbf{c}$, except for longitudinal cross sections along $0^{\circ}-10^{\circ}$ N. g-i Similar to a-c,

of the two CAM3 results with the ERA-40 results finds much too small (by $>50 \%$ ) diabatic heating along most of the ICZ and SPCZ in CAM3 whether using Eqs. 7 or 8. See

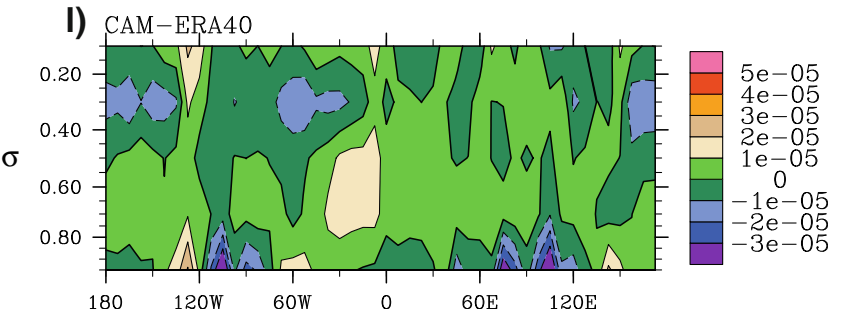

except for longitudinal cross sections along $30^{\circ}-40^{\circ} \mathrm{N}$. This cross section picks up the NPST and start of the NAST. $\mathbf{j}-\mathbf{l}$ Similar to $3 \mathrm{a}-\mathrm{c}$, except for longitudinal cross sections along $40^{\circ}-50^{\circ} \mathrm{N}$. This cross section picks up most of the NAST

Fig. 4c, f, respectively. The precipitation is much less in CAM3 and the ICZ and SPCZ cloud tops are presumably not as high since net radiation is greater in CAM3 (not 
Fig. 4 Vertically integrated diabatic heating calculated two ways: as a residual, Eq. 7, in the temperature equation (left column) and using boundary sources, Eq. 8, of precipitation, surface sensible heat flux and top of atmosphere net radiation (right column). The top row a and d use ERA-40 data; the middle row $\mathbf{b}$ and $\mathbf{e}$ use CAM3 data. The bottom row compares the bias. The units are $\mathrm{W} \mathrm{m}^{-2}$

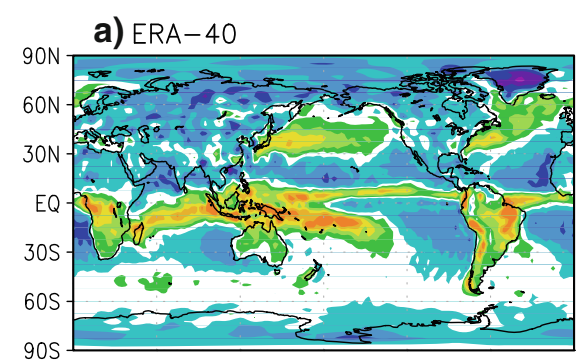

b) CAM

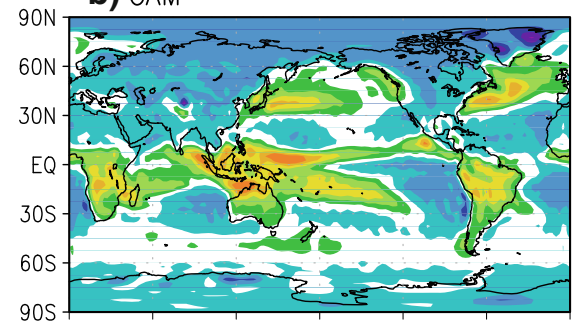

c) $C A M-E R A 40$

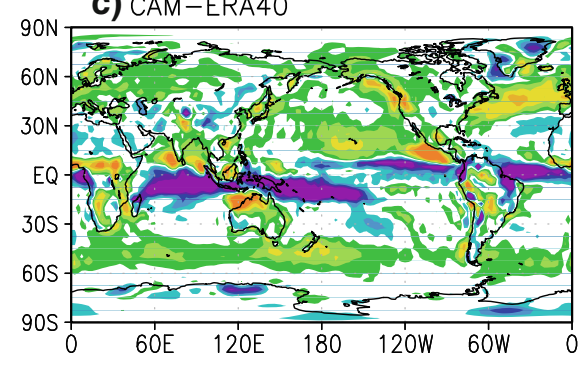

d) $E R A-40$

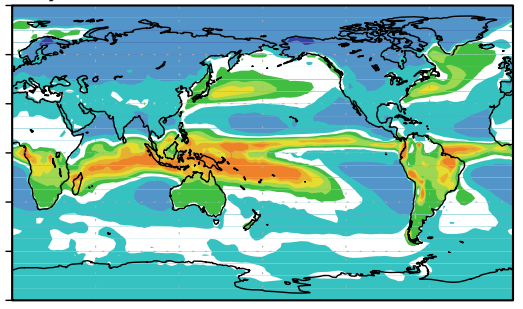

e) CAM

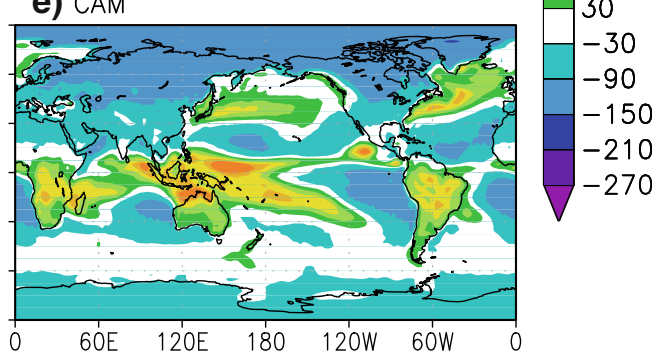

f) $C A M-E R A 40$

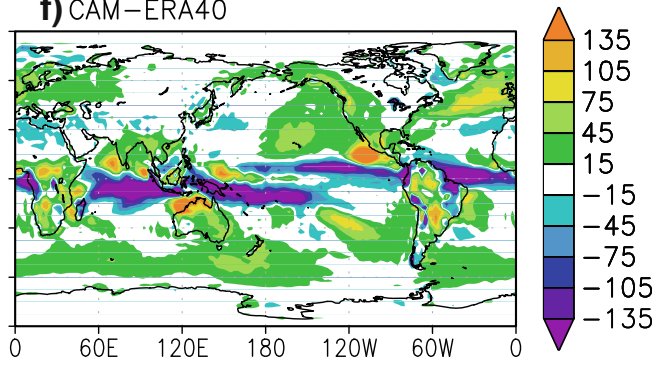

shown). In the equatorial western Pacific and Indian Ocean, the difference field has strongly negative sign between $5^{\circ} \mathrm{N}$ and $10^{\circ} \mathrm{S}$ and positive sign to the north and over northern Australia. In the equatorial eastern Pacific and Atlantic ICZ region, the difference field also has a negative sign along the ICZ. A large positive region is present south of Mexico; it is entirely due to CAM3 having heavy precipitation there. These features are consistent with the patterns shown in Fig. 2 and appear whether the residual or boundary heat sources are tallied.

Figure 5 shows $Q_{1}$ plus the individual boundary contributions to $Q_{1}$ for latitudes north of $30^{\circ} \mathrm{N}$ in ERA-40 (Fig. 5a-d), CAM3 (Fig. 5e-h), and the bias field (Fig. 5i1). Along the entire NAST, but especially from the midpoint onward, CAM3 has much larger (by upwards of 50\% more) integrated heating than ERA-40 (Fig. 5d, h, 1). Most of the bias $(\sim 2 / 3)$ in the middle and downstream end of the NAST is from precipitation, with most of the remainder $(\sim 1 / 3)$ from net radiation (Fig. 5i, k). Precipitation in the eastern Atlantic is lighter and more widely spread (in latitude) in ERA-40. Net radiation is more strongly negative over the Atlantic in ERA-40. However, further downstream, the net radiation is less negative in ERA-40 over the middle latitudes from the Mediterranean Sea across the Middle East and Asia to the Pacific coast making the net radiation bias negative across that region (Fig. $5 \mathrm{k}$ ). The residual calculation in this region has negative values in the lowest levels which seems consistent with the pattern of net radiation (Fig. 5k) and with excessive low cloud cover in CAM3 (CAM3 loses more radiative energy and reflects more sunlight than the ERA-40 data). Surface sensible heat flux, Fig. 5j, is the largest contributor to the (positive) bias along the North America Atlantic coast near the start of the NAST. This sensible heat flux is more strongly positive in CAM3 along the east coasts of North America and Greenland and into the Barents Sea. Over Russia and part of the ice-covered Arctic Ocean, the sensible heat flux bias is not as strongly negative in CAM3 as ERA-40, causing the positive bias seen there in Fig. 5j. Again, the pattern seen in boundary-deduced $Q_{1}$ (Figs. 51, 4f) versus a residual (Fig. 4c) agree pretty well along the NAST. Along the NPST, CAM3 total heating is notably less ( $\sim 30 \%$ less) near the start of the track and ( $\sim 50-100 \%)$ more along the North American west coast (the range accounting for the differences noted above between Fig. 4b, e). The negative bias at the start of the NPST is mainly due to surface sensible heat flux being much smaller in CAM3 (Fig. 5j). Surface sensible heat flux extends much further eastward from Asia in ERA-40 than in CAM3. At the downstream end of the NPST, the surface heat flux is positive. So along 
a) Precipitation

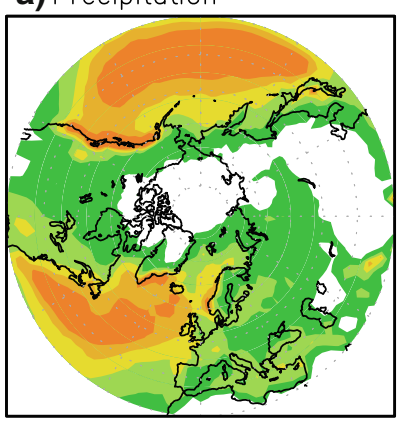

c) net radiation
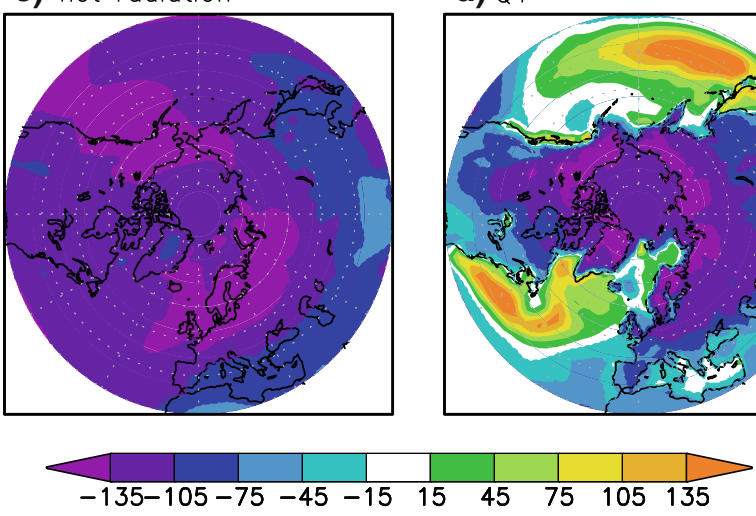

e) Precipitation

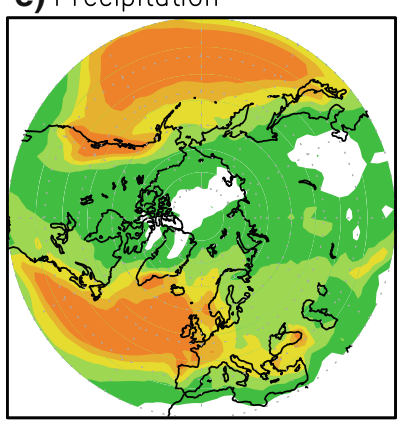

g) net radiation

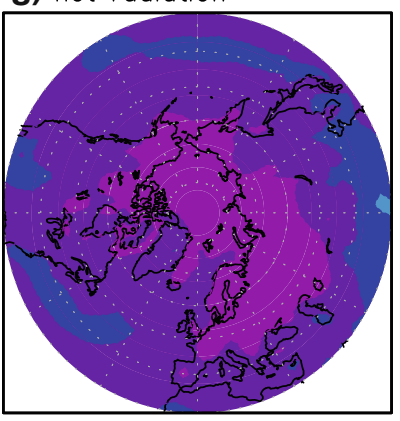

h) Q1
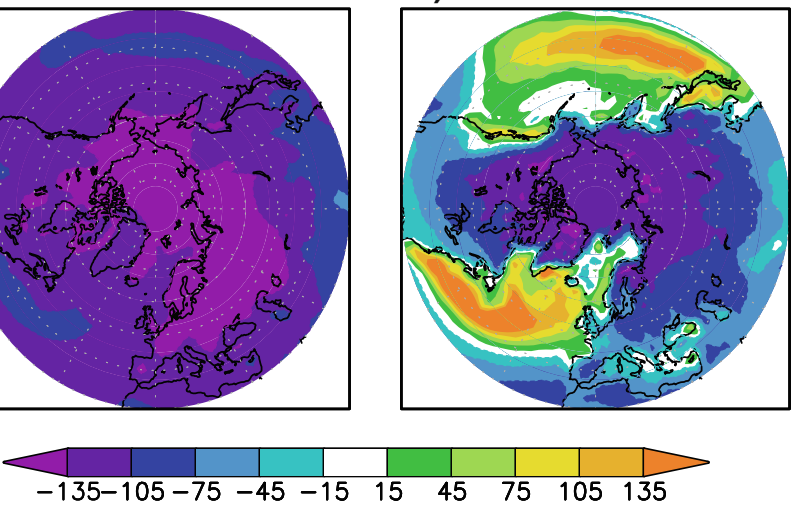

Fig. 5 a-d Boundary contributors of ERA-40, a precipitation, b surface sensible heat flux, and $\mathbf{c}$ top of atmosphere net radiation to the vertically integrated diabatic bias, $Q_{1}$ shown in (d). The units are
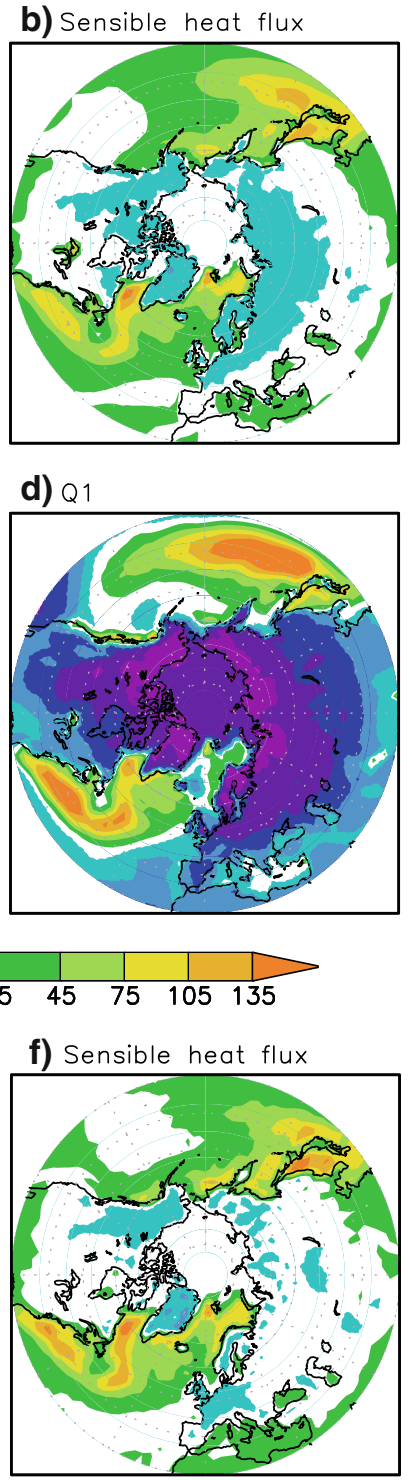
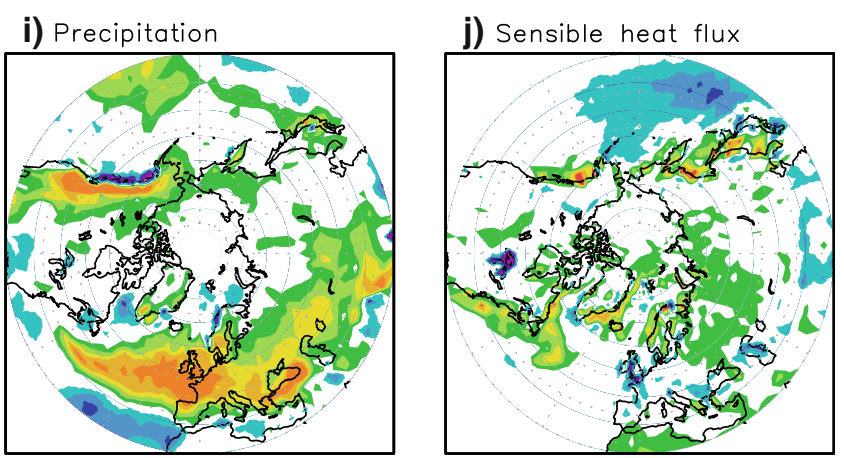

k) net radiation

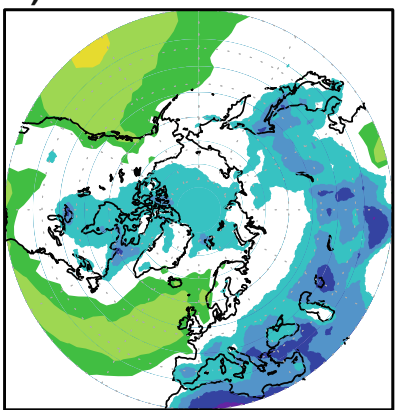

I) $Q 1$
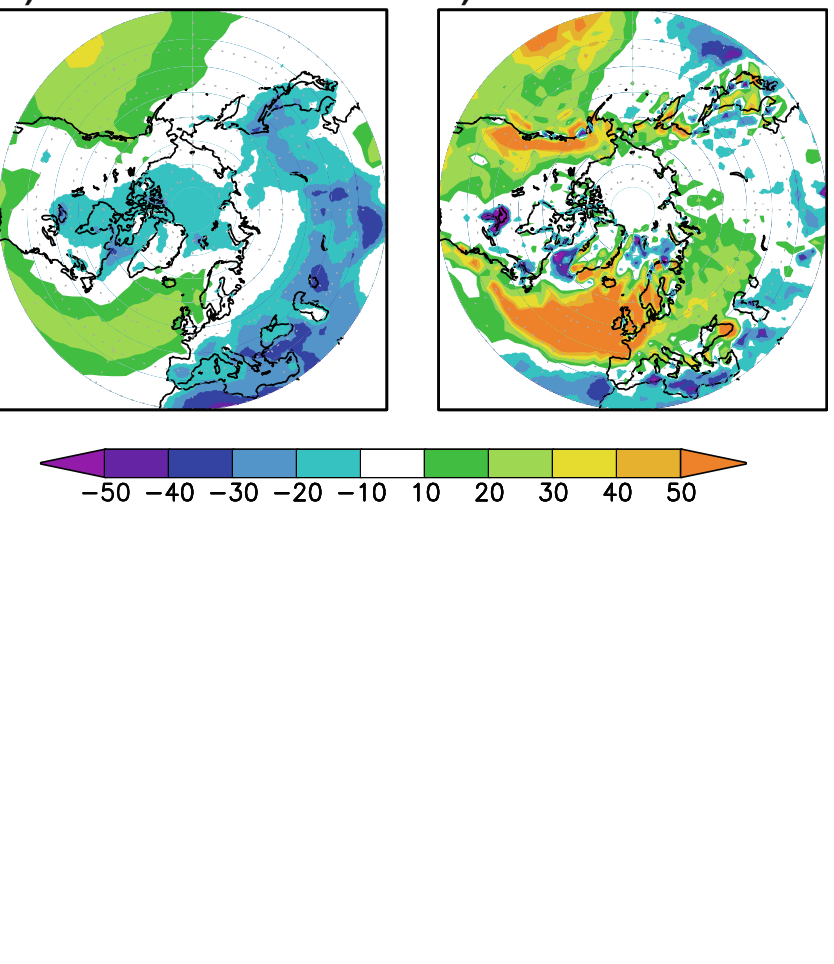
the NPST, CAM3 surface heat flux bias has the opposite pattern as it does for the NAST. ERA-40 net radiation is more strongly negative over the Pacific, similar to the Atlantic track. Hence the net radiation bias is positive (Fig. 5k) especially on the downstream and subtropical sides of the Pacific storm track. Precipitation is enhanced near the west coast of North America in both ERA-40 and CAM3; however, the strong precipitation is about twice as wide longitudinally in CAM3 and not as strong right at the coast. The result is a rapid sign change of precipitation bias seen in Fig. 5i. The small scale of the precipitation change (and even more so in $Q_{1}$ ) along the North American west coast may explain the disagreement in $Q_{1}$ estimates using Eqs. 7 versus 8 discussed in connection with Fig. 4c, f.

Our calculations use ERA-40 estimates of precipitation, $P$, but other estimates of $P$ exist. Hurrell et al. (2006, their Fig. 16) find a similar pattern of excessive $P$ during DJF on the downstream end of the NAST. Hurrell et al. use climate prediction center merged analysis of precipitation (CMAP) data (Xie and Arkin 1996). Similarly, they also find a positive $P$ bias in the mid Pacific along the NPST when comparing CAM3 with CMAP. Similar to the ERA-40 data, CMAP does not extend the NPST $P$ as far into North America as does CAM3. Hack et al. (2006b, their Fig. 19) compare annual mean $P$ between CAM3 and CCSM3 and find similar $P$ bias over Europe and adjacent Atlantic waters. CCSM3 and CAM3 differ more along the NPST than along the NAST, though CCSM3 still carries the NPST $P$ too far into North America. Dickinson et al. (2006, their Fig. 4) show a similar elongated dipolar $P$ pattern along the North American west coast and excessive $P$ over Europe when comparing CCSM3 with observations from the Willmott and Matsuura (2000) dataset. In short, other $P$ datasets find similar CAM3 bias.

The results of this section suggest that discussion of diabatic heating bias is likely robust across the NAST and most of the NPST (except along the North American west coast). So, we shall not emphasize results near the North American west coast. The precipitation along the NAST is generally greater, but the net radiation less in CAM along much of the NAST. Clearly the frontal cyclones of the north Atlantic have quite different behavior in CAM than ERA-40. In contrast, frontal cyclones in the NPST seem to have more similar tracks in ERA-40 and CAM. Precipitation does not have as large of a positive bias in the NPST, though net radiation is similarly less (positive bias). Another difference is the surface sensible heat flux at the track start has opposite sign from the NPST to the NAST. Because the two tracks differ it is hard to generalize about the model error. We note that the observed NAST differs from the NPST in being much more curved (and tending towards a higher latitude on the downstream end) and both tracks are straighter in CAM3 (Fig. 2b) than in ERA-40 (Fig. 2a).

Trenberth and Smith (2009) also formulate a vertically integrated moisture equation such that the boundary moisture source for the atmosphere is precipitation $(P)$ minus evaporation $(E)$. When multiplied by the latent heat parameter ( $L$, which may be allowed to vary) one obtains a moisture equation 'apparent heat source', $Q_{2}=L \times(P-$ $E$ ). They further form a total energy equation whose total diabatic heating is $Q_{1}-Q_{2}$. Hence $Q_{1}-Q_{2}$ provides a window upon the total energy forcing bias. Another advantage of considering $Q_{2}$ is that Trenberth and Smith remark that $Q_{2}$ is relatively less sensitive to the method of calculation, so it is shown here in part as a check upon the contribution by $P$ to $Q_{1}$.

Figure 6 shows the diabatic heating contributions to temperature, moisture, and total energy for ERA-40, CAM3, and the respective biases. $Q_{2}$ shows much cancellation by $E$ of the contribution by $P$, however, $P$ remains large on the downstream ends of the NAST and NPST. $Q_{2}$ bias (Fig. 6f) is negative over Gulf Stream indicating excess evaporation over precipitation. Precipitation bias is positive there (Fig. 5i) as was sensible heating (Fig. 5j) so a negative sign in $\mathrm{Q}_{2}$ implies even larger bias in $E$ (with much larger values in CAM3). It is interesting that ERA-40 values of surface sensible heat $(\mathrm{SH})$ and surface latent heat fluxes are both $\sim 25 \%$ greater in ERA-40 than NCEP/DOE AMIP reanalysis II (NDRA2) over the Gulf stream (Grotjahn 2009). Apparently CAM3 is even larger than NDRA2 in that region. For the region off Japan at the start of the NPST, the bias is somewhat different: $\mathrm{SH}$ is smaller than ERA-40 in CAM3, though the biases in $P$ and $E$ are similar to that over the Gulf Stream (so the bias in $Q_{2}$ there is small). On the downstream end of the NPST and NAST, $\mathrm{Q}_{2}$ becomes positive as $P$ exceeds $E$ (and where $P$ is greater in CAM3 than in ERA-40).

The diabatic heating contributions to total energy $\left(Q_{1}-Q_{2}\right)$ show the expected (e.g., Trenberth and Smith 2009) energy input at the starts of the NAST and NPST. Energy loss occurs over the downstream ends of the NAST and NPST as well as over the continents and ice-covered Arctic Ocean. Interestingly, the bias shows opposite patterns of net input and removal along the NPST and NAST. Less energy is input at the start and less is removed at the end of the NPST. However, the energy input at the start of the NAST is greater in CAM3 and the removal to the west of Europe is much less in CAM3 as can be seen in the ERA-40 and CAM3 maps (Fig. $6 \mathrm{~g}, \mathrm{~h}$ ) of $Q_{1}-Q_{2}$, as well as the corresponding bias.

In summary for the NAST: CAM3 has greater sensible heat flux at the start, evaporation all along the NAST is greater but so is precipitation, the greater precipitation extends eastward into western Asia, where (negative) net 
Fig. 6 Vertically integrated diabatic heating in a ERA-40 and $\mathbf{b}$ CAM3 data and their bias c for latitudes north of $30^{\circ} \mathrm{N}$, otherwise comparable to $\mathbf{d}-\mathbf{f}$. Plot c, same as $\mathbf{d}$, is shown here for reference. Middle column $\mathbf{d}-$ f are corresponding quantities of vertically integrated boundary moisture contribution expressed as heating [latent heat times (precipitation minus evaporation)]. $\mathbf{g}-\mathbf{i}$ are corresponding quantities for a total energy equation. Units are $\mathrm{W} \mathrm{m}{ }^{-2}$
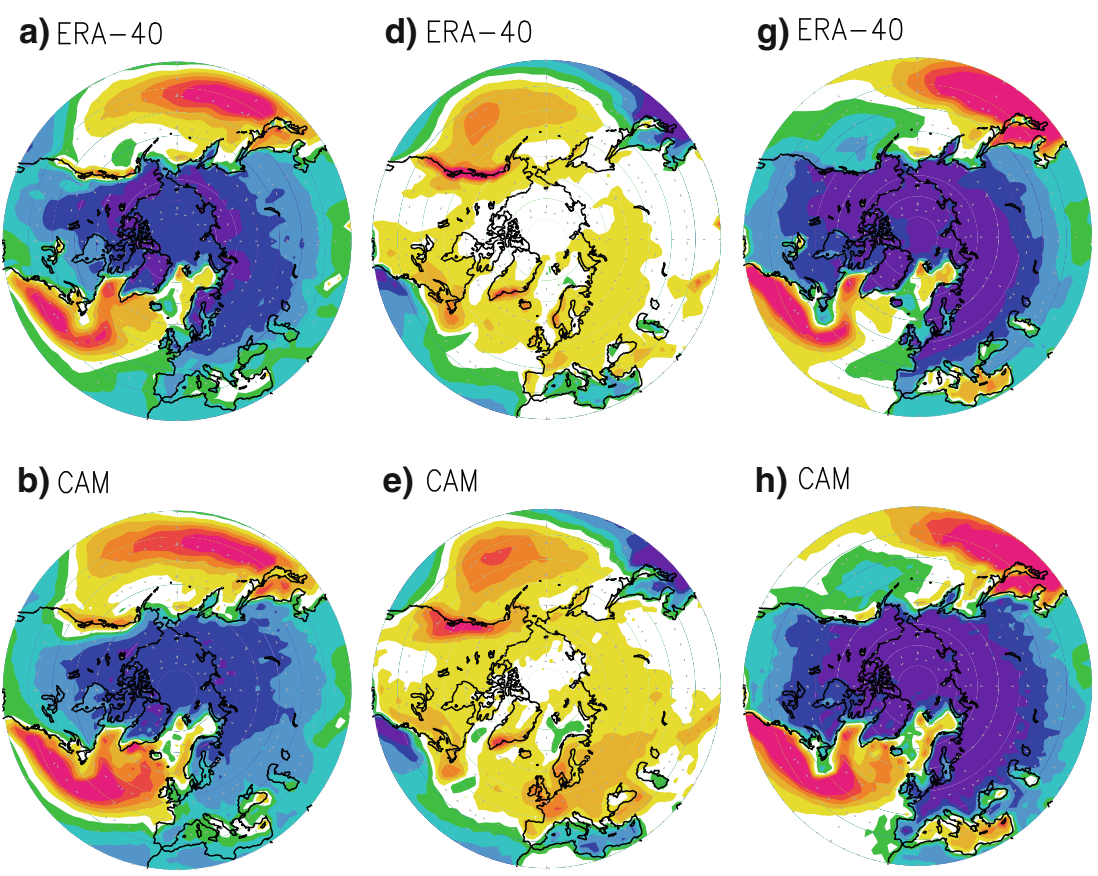

c) CAM-ERA40

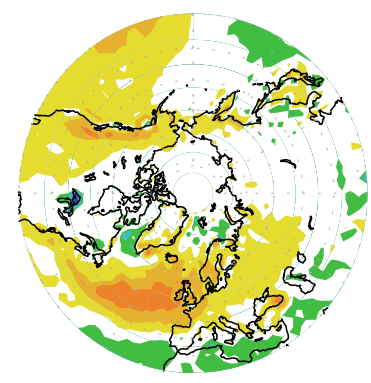

Q1 e) CAM

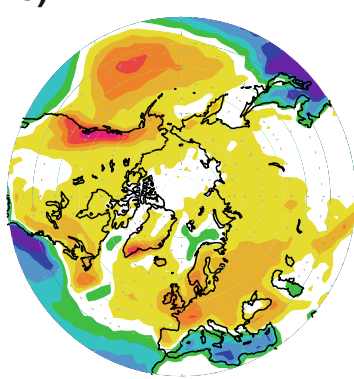

f) CAM-ERA40

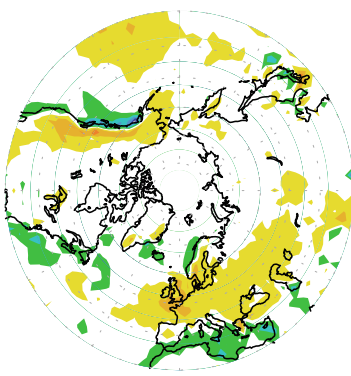

Q2 h) $\mathrm{CAM}$

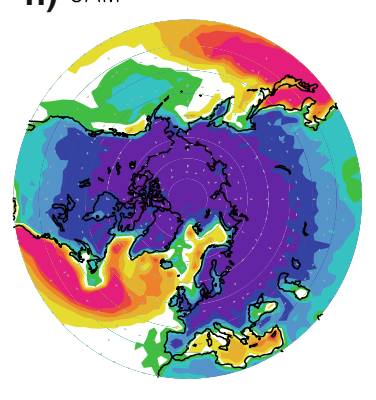

i) CAM-ERA40

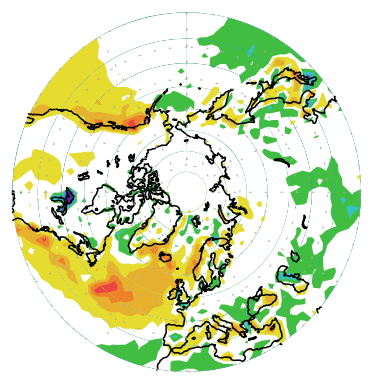

Q1-Q2 radiation to the south is also stronger; while these diabatic processes are stronger in CAM3, the transient heat flux is not noticeably stronger except near the west coast of Europe (due to the storm track error). In summary for the NPST: CAM3 starts off with weaker surface heat flux, precipitation grows stronger by the mid Pacific (again largely balanced by greater evaporation in the model); so the upstream end gains less energy while the downstream end has correspondingly less loss of energy compared to ERA-40.

\section{Linear advection term, nonlinear advection term, and storm track forcing}

We also calculated the linear advection terms (Linear Group), nonlinear advection terms (Nonlinear Group), and transient heat flux terms contribution to the time mean (Transient Group) in the bias Eq. 4 by using ERA-40 and CAM3 simulation data. Our approach in discussing these terms is twofold. First, we seek to isolate physical processes that create portions of the bias by making this partitioning. Second, we want to assess the strength of the terms, including both the dominant physical processes but also the size of the nonlinearity. In the previous section we discussed various contributions to the diabatic heating, but that is not the only source of bias. Bias may result from transient activity (Transient Group) that contributes to the time mean, and for the temperature equation these are vertical and horizontal heat fluxes by the transient components. The remaining terms (Nonlinear Group) arise when the bias interacts with itself.

Figure 7 shows the Linear Group, Nonlinear Group, and Transient Group over the globe at three representative levels chosen to match the diabatic heating levels shown (recall Fig. 1).

The upper troposphere pattern is seen in Fig. 7a-c. The Linear Group (Fig. 7a) is largest and so has much similarity to the diabatic heating shown in Fig. 1c. Along the ICZ 
and in the Pacific south of Mexico the nonlinear terms (Fig. 7b) have similar pattern but about half the magnitude as the diabatic bias (Fig. 1c). In subtropical and higher Northern Hemisphere latitudes at this level the Nonlinear Group is generally much smaller compared to other terms. The transients (Fig. 7c) also has some contribution to the bias along the ICZ in the Indian and western Pacific Oceans. Transients have their larger values along the NAST and the NPST. There is some cancellation between diabatic (Fig. 1c) and transient (Fig. 7c) heating for the first half of the NAST and the second half of the NPST. For the first half of the NPST there is less cancellation than seen in the NAST because the contributions by diabatic and transient heating are offset in latitude (making the dipolar pattern of the Linear Group at the start of the NPST). The results at this level suggest that a linear model could be appropriate if interaction with the ICZ bias is not important.

In the middle troposphere, one sees almost no notable contribution by the nonlinear terms (Fig. 7e). Transient terms (Fig. 7f) have less contribution than they did higher up, with a negative forcing in the NPST that is opposite to the transient forcing above (Fig. 7c). The Linear Group still has a positive forcing bias along middle and downstream end of the NAST, but the middle portion is due mainly to diabatic heating while only a small area near Norway arises from the transients. The forcing at this level is clearly dominated by the diabatic heating.

In the lower troposphere $(\sigma=0.85$, Fig. $7 \mathrm{~g}-\mathrm{i})$ the primary balance to the linear terms (Fig. 7g) is again the diabatic heating bias (Fig. 1i). Along the NAST, the transient terms (Fig. 7i) are much weaker than at upper levels. The most notable transient contribution is along the downstream half of the NPST, where the bias in the transients generates cooling. The transient cooling near the southeast Alaskan coast has the opposite sign to the transients bias at upper levels (Fig. 7c) and strongly opposes the diabatic heating (Fig. 1i) here. Unlike middle and upper levels, nonlinear bias terms (Fig. 7h) now have a few contours in middle and high latitudes. At the lowest model level ( $\sigma=0.95$, not shown) the nonlinear terms become comparable to the transient and diabatic terms over polar land areas from Norway eastward into Alaska.

The results show that the Linear Group of terms tends to be the largest group in most locations and levels. In many cases it is balanced by diabatic heating, which was obtained as a residual. The transients have notable contribution in the NPST and NAST in middle and upper troposphere. The nonlinear terms are much smaller in subtropical and higher latitudes except close to the surface.

Longitudinal cross sections of the Linear, Nonlinear, and Transient Groups are shown in Fig. 8. The Nonlinear and Transient Groups have little contribution in the tropical belts shown in Fig. 3 and so are not shown. The Linear
Fig. 7 a-c Groups of terms in the temperature bias equation at $\sigma=0.3$ : a linear terms in the bias, $\mathbf{b}$ nonlinear bias terms, and $\mathbf{c}$ all transient contributions to the time mean temperature bias equation. The contour interval is $10^{-5} \mathrm{~K} \mathrm{~s}^{-1}$. Dashed contours used for negative values. $\mathbf{d}-\mathbf{f}$ Similar to $\mathbf{a}-\mathbf{c}$, except at $\sigma=0.5$. $\mathbf{g}-\mathbf{i}$ Similar to a-c, except at $\sigma=0.85$

Group for tropical belts looks very similar to Fig. 3c and f; the only notable difference is a small amount of added negative forcing at upper levels across the Indian and Pacific Oceans ICZ and Amazonia by both nonlinearity and transients (recall Fig. 7b, c).

The forcing along middle latitude bands is more interesting. To capture the larger biases seen in Fig. 7 along the NAST (and the later half of the NPST), we consider the latitude band between $40^{\circ}$ and $50^{\circ} \mathrm{N}$. In this band the upper level positive contribution along the downstream half of the NAST by the transients (Fig. 7c) also seen in the Linear Group (Fig. 7a) is seen again in Fig. 8c. Further downstream of the NAST (and the downstream end of the NPST) the transients have negative contribution to Linear Group in middle and lower levels.. At the start of the NAST, the diabatic heating (Fig. 8d) has opposite sign at lower and upper levels. At upper levels of the NPST diabatic heating bias is generally negative. The diabatic heating forcing tends to be larger at lower tropospheric levels and is mainly positive at the upstream ends of the NAST and NPST. The negative diabatic heating over both continents is seen to be quite shallow. The contributions by nonlinear terms (Fig. 8b) are seen to be small nearly everywhere.

Finally, one can further subdivide the linear bias terms (Linear Group) into vertical and horizontal advection of temperature (either by the bias or of the bias). Doing so finds the vertical advection tends to be larger than horizontal in the tropics and the horizontal somewhat larger in middle and high latitudes. In the upper troposphere, the two have quite a bit of cancellation in the middle and high latitudes. The four parts of the Linear Group were individually plotted (not shown) for middle and high latitudes. The vertical advection by the mean flow is the smallest and negligible. The other three terms are individually much larger than their combination shown before (e.g., Fig. 7a). In the upper troposphere, there is much cancellation between the horizontal advection terms and vertical advection by the bias flow term along and to the north of the NAST and along most of the NPST. For example, over the northeast Pacific and over Japan horizontal advection by the mean flow and vertical advection by the bias combine to overcome the opposite (positive) sign of the horizontal advection by the bias. The negative area in Fig. 7a over eastern Canada is mainly from horizontal advection by the mean flow (the two terms with advection by the bias again cancel). The positive region (Fig. 7a) over western 
a) Linear Group

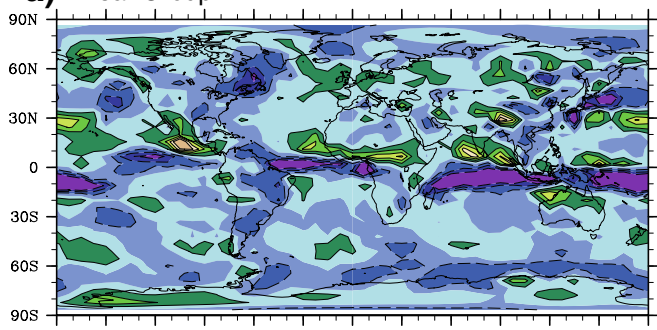

b) Nonlinear Group

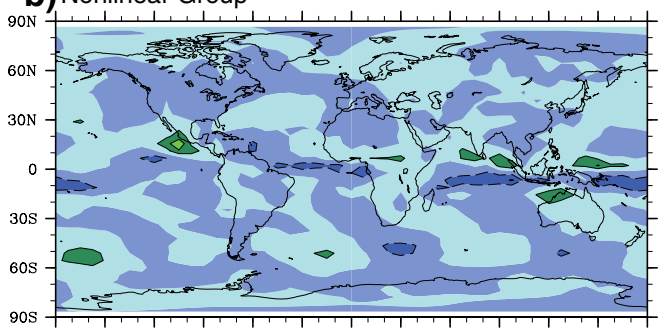

C) Transient Group

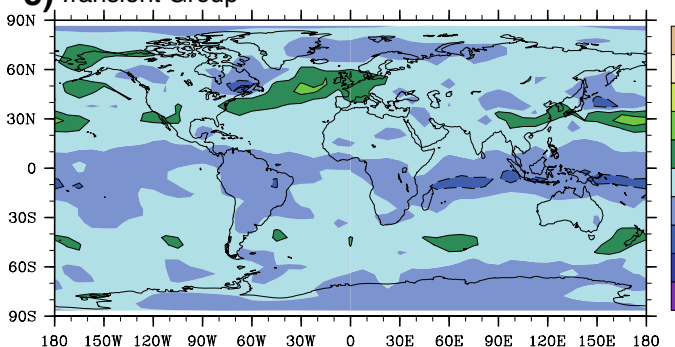

d) Linear Group

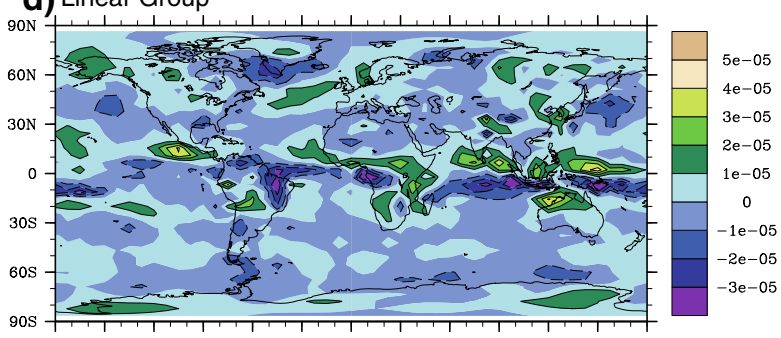

e) Nonlinear Group
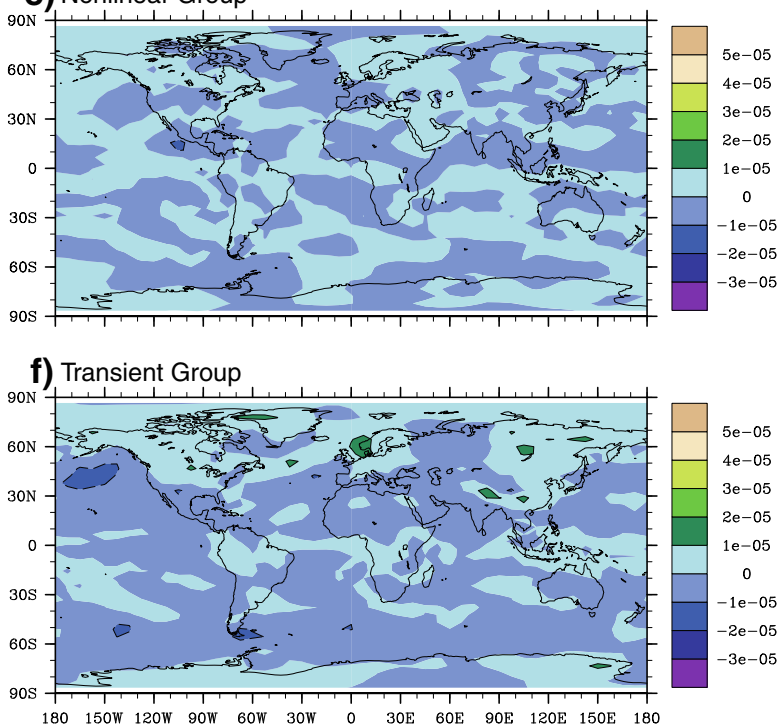

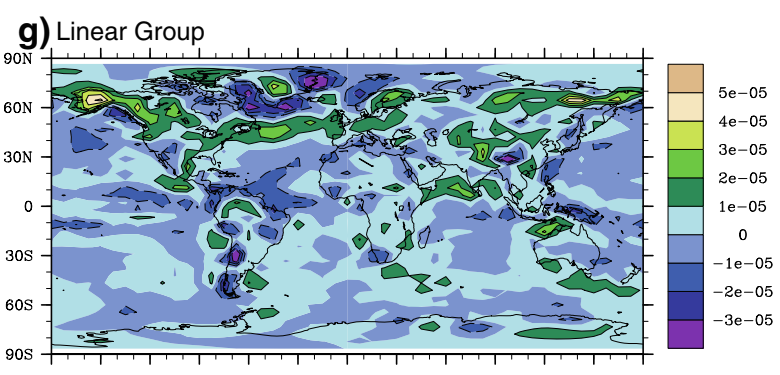

h) Nonlinear Group

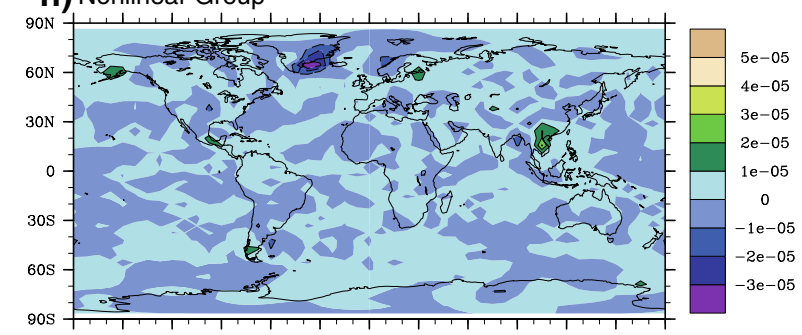

i) Transient Group

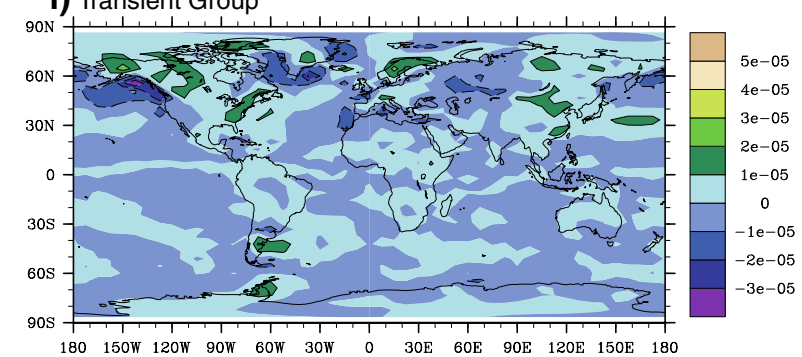




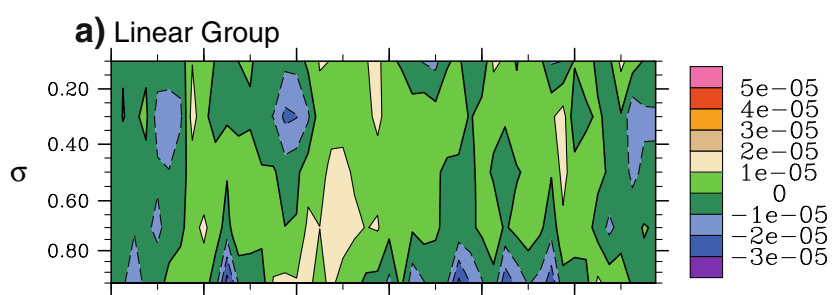

b) Nonlinear Group
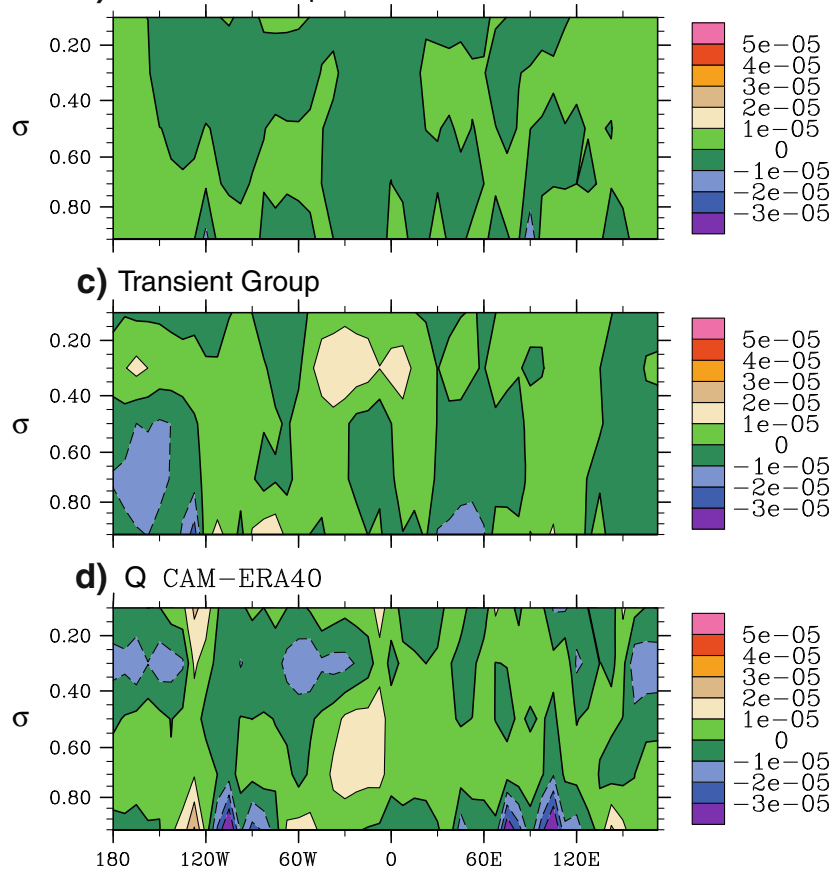

Fig. 8 Longitudinal cross sections at $40^{\circ}-50^{\circ} \mathrm{N}$ comparing the Linear Group of terms to the other groups of terms in the temperature bias equation. Units are $\mathrm{W} \mathrm{m}^{-2}$

Europe is a combination of horizontal advection by the mean flow combined with vertical advection by the bias flow (to overcome the horizontal advection by the bias). In the lower troposphere there is also much cancellation between the two advection by the bias flow terms. However, the positive area along the middle of the NAST and the negative areas wrapping around southern Greenland (Fig. 7g) are both places where all 3 terms reinforce each other. So, there is not one single member or combination of terms that dominates the entire storm track or even most of it, though the two advection terms were most commonly cancelling.

The transient (or eddy) forcing to the mean field can be further investigated by an Eliassen-Palm (EP) flux analysis (see Eq. 10.20 in Holton 1992), Fig. 9 gives the zonal-mean zonal wind and EP flux of ERA-40, CAM3, and their difference. Divergence of EP flux can be related to maintenance of the zonal mean zonal wind. In Fig. 9, this association is most prominent for the subtropical jet; CAM3 has a little stronger EP flux divergence than ERA-40
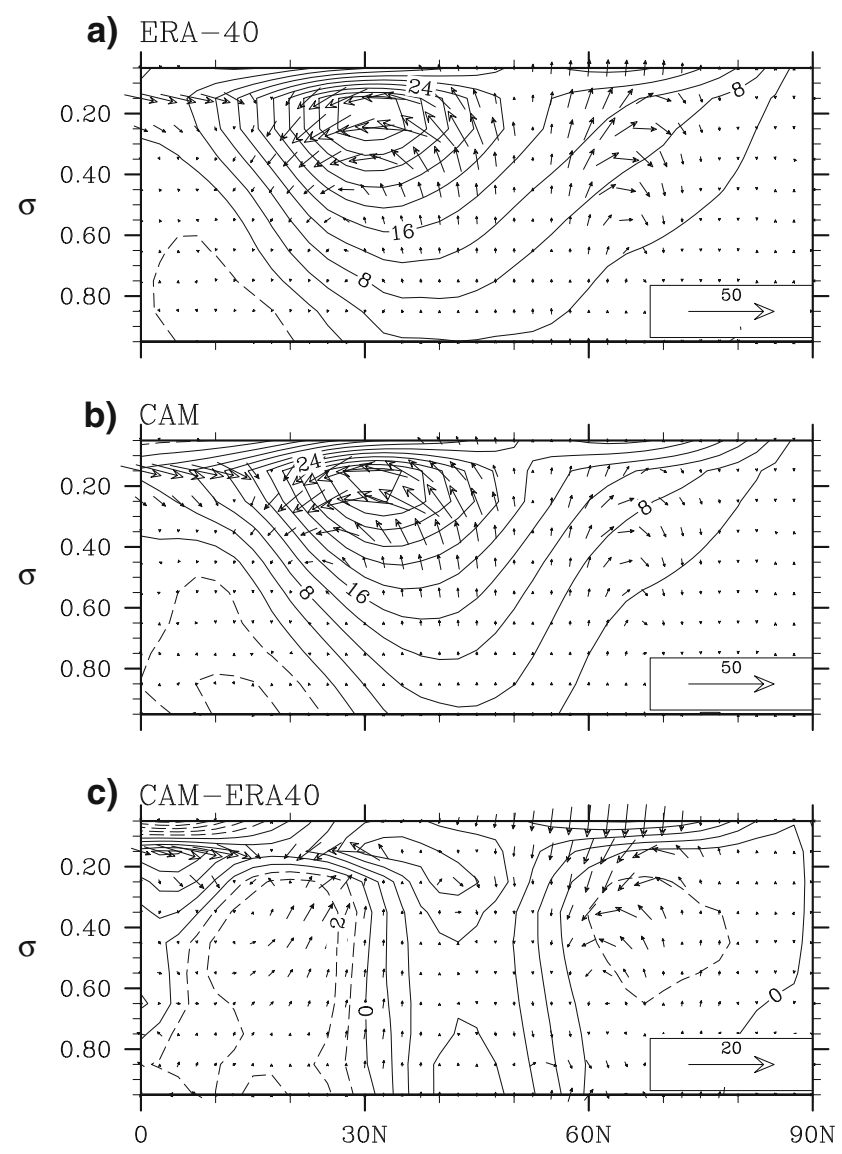

Fig. 9 Meridional cross sections of zonal-mean zonal wind (contour lines) and EP flux (vector) during DJF. a ERA-40, b CAM3, c and the CAM model bias (CAM3-ERA-40 difference). Dashed contours used for negative (i.e., easterly) zonal winds. The vector scale is given in the lower right of each plot

consistent with the stronger zonal wind. An additional upper level EP flux divergence occurs near latitude $60^{\circ} \mathrm{N}$ and in that case ERA-40 is stronger, consistent with weak zonal mean flow there in CAM3 (Fig. 9c). EP flux can also be viewed as a flux form of wave activity advection and to that end the poleward flux (between $60^{\circ}$ and $70^{\circ} \mathrm{N}$ ) is clearly weaker in CAM3.

In summary, the large size of the diabatic heating and cooling described in Sect. 4 is largely balanced by the linear advection terms, especially the horizontal advection terms and vertical advection by the bias winds. Transient heat flux terms are notable in the NAST and NPST. Except quite close to the surface, nonlinear interactions between the bias temperature and wind fields is neglectable.

\section{Precipitation and Arctic bias}

It was shown above that a large diabatic heating forcing exists in the downstream end of the NAST. This positive bias arises mainly from excess precipitation $(P)$ and 
secondarily from less net radiation in CAM3. In a linear model calculation (not shown) we have found some evidence that diabatic forcing bias in the NAST can create a SLP solution over the European side of the Arctic region that is similar to the SLP bias. An obvious question is whether $P$ bias on the downstream end of the NAST has a connection to the Arctic surface climate bias or vice versa in CAM3. Here we test the timing and possible connection between precipitation west of Europe and the high latitude sea level pressure (SLP). The testing is done by calculating 1-point correlations (e.g., as in Grotjahn and Osman 2007) using SLP 2-dimensional data that lead or lag a time series of $P$ at a 'correlation point'. Figure 10 shows the results of such a comparison using CAM3 data. CAM3 data are used for $P$ and SLP since we want to see how the model is responding to $P$ occurring where the $P$ bias is large.

Before discussing the 1-point correlations, it is useful to review the Arctic surface bias during winter. Figure 10d shows the SLP bias (based on ERA-40 data) over the 20year 1979-1998 period. For CAM3, the SLP is generally lower than ERA- 40 over most of the area north of $50^{\circ} \mathrm{N}$. Of particular interest is the small area of positive bias (CAM3 having higher SLP than ERA-40) centered in the Barents
Sea around the Novaya Zemlya islands. This relatively higher SLP over the Barents Sea has been a persistent feature of the NCAR community climate models for more than a decade; it is found in different NCAR models and at different resolutions of those models. Some NCAR model versions have (averaged over the polar cap north of $50^{\circ} \mathrm{N}$ ) overall higher SLP or overall lower SLP than that shown here, but the relative pattern: negative bias over northern Europe and the Beaufort Sea plus relative positive bias over the Barents Sea has remained. So, while the positive area centered over Novaya Zemlya may look unimpressive in Fig. 10d, it is an important feature to understand about the Arctic surface climate bias.

Figure 10a-c show a progression of lags by the SLP field relative to the precipitation at $7.5^{\circ} \mathrm{W}, 45^{\circ} \mathrm{N}$ (the correlation point, marked by a large dot). Low pass filtered data are used to remove the transient wavetrain associated with a progression of highs following lows along the CAM NAST. In other words, the low pass filtering emphasizes the longer term result of having persistent greater precipitation at the correlation point. The filtering used in Fig. 10a-c removes periods shorter than 10 days with a 101-point Lanczos filter. The patterns are not sensitive to
Fig. 10 Correlations between precipitation $(\mathrm{P})$ at the $7.5^{\circ} \mathrm{W}$, $45^{\circ} \mathrm{N}$ correlation point with sea level pressure (SLP) of $30^{\circ} \mathrm{N}$. All data are from 20 years of CAM3 simulated DJF. Various lags and leads are shown. Low pass filtering has removed periods shorter than 10 days. a SLP occurs 3 days before P; b SLP and P occur at same time (no lag); and c SLP occurs 3 days after P. Contour interval 0.1 with the $-0.1,0$, and 0.1 contours suppressed. d SLP bias in CAM3 using $2 \mathrm{hPa}$ contour interval. Shading is used to indicate the correlation is significant at the $1 \%$ level. Dashed contours used for negative values
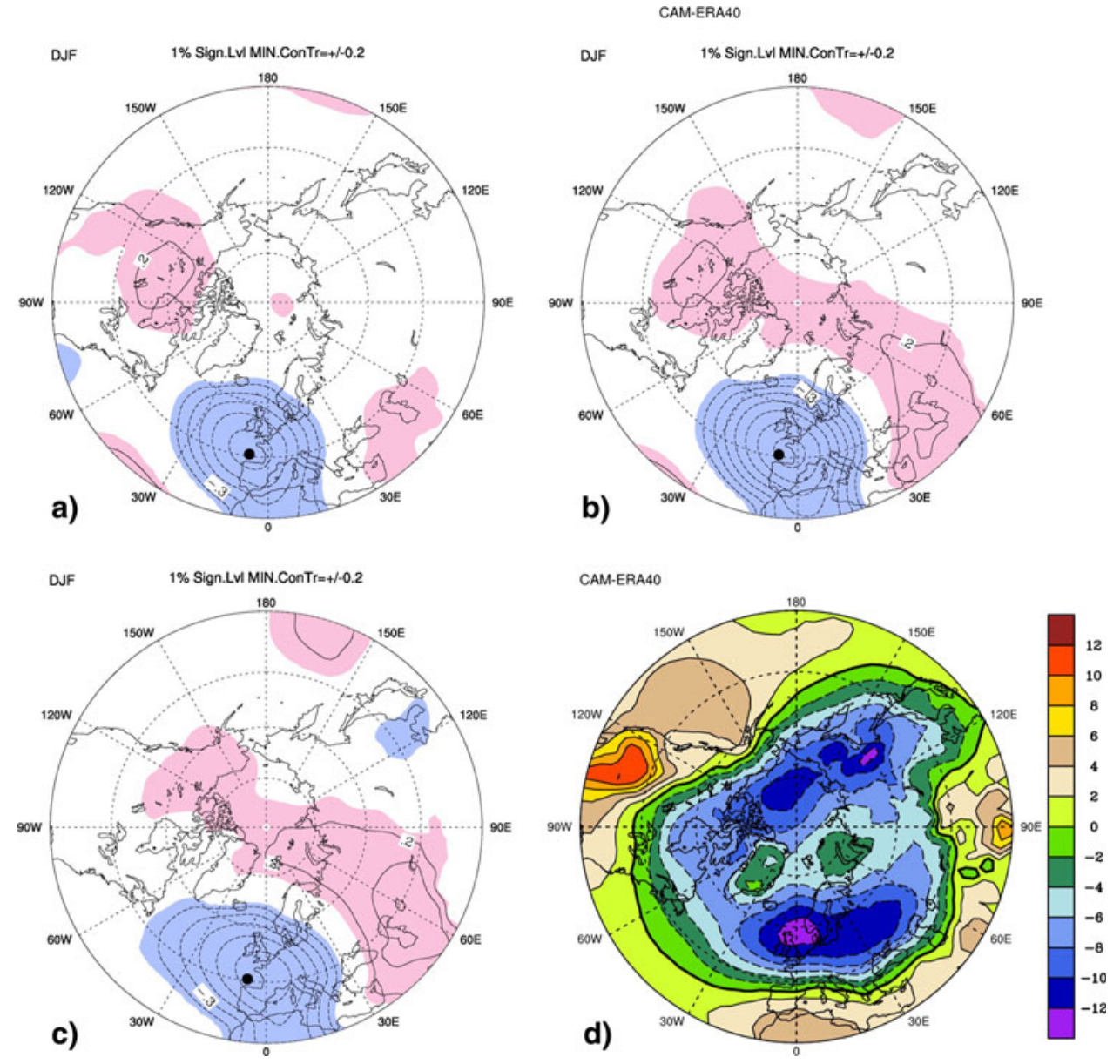
the filtering, removing only periods shorter than 5 days obtains similar plots. Figure 10a correlates the SLP 3 days before the $P$; Fig. 10b has zero lag; Fig. 10c correlates SLP 3 days after the $P$. Focusing on the Arctic region, it is obvious that there is a clear preference over the Barents Sea and adjacent northwestern Russia for higher SLP to follow the higher $P$ at the correlation point. If there was no preference for timing or if the SLP led the $P$, then such a result would disprove the notion that the NAST diabatic heating bias (related to $P$ bias) somehow 'forces' (helps create) the Barents Sea SLP bias. In summary, the $P$ change leading the SLP change in Fig. 10 is consistent with diabatic heating by the $P$ bias leading to higher SLP over the Barents Sea, though it does not prove the forcing link. Linear model results (not shown) suggest that the bias is related to the localized forcing, not the remote forcing (e.g., tropics).

\section{Summary}

This paper investigates the simulation error of CAM3 by diagnostic study of the temperature bias equation. We ran a 20-year simulation with CAM3 and use ECMWF (European Centre for Medium-Range Weather Forecasts) 40 year reanalysis (ERA-40) data for verification and to obtain the forcing fields associated with the temperature bias equation. The diabatic heating field, defined as the residual, is obtained from the temperature equation. To gain confidence in this residual we compare a vertical integral of that residual through the entire atmosphere with boundary sources of diabatic heating: precipitation $(P)$, surface sensible heat flux (SH), and top of atmosphere net radiation $(R) . P$ times $L, \mathrm{SH}$, and $R$ should add up to the vertically integrated diabatic heating and to an adequate degree they do.

In the tropics, the diabatic heating dominates. The primary contributor by far to the diabatic heating bias is $P$. The ICZ is generally weaker in CAM3 (almost missing in the Atlantic) while CAM3 emphasizes ICZ-like diabatic heating in the northern hemisphere (NH). In CAM3, the Indian Ocean ICZ is shifted into the $\mathrm{NH}$, and the $\mathrm{NH}$ heating is emphasized in the western Pacific. In the far eastern Pacific CAM3 has strong ICZ-like heating where ERA-40 has cooling. Nonlinear and Transient Groups of terms largely reinforce the diabatic heating bias in the upper tropical troposphere. CAM3 also does not reproduce as much upper level diabatic heating as seen in ERA-40.

In middle latitudes, the attention centers on the NPST and NAST storm tracks. The bias at the start of these storm tracks differs: at low levels it is positive at the start of the NAST but negative at the start of the NPST. There is notable $\mathrm{SH}$ and evaporation bias at the NAST start; both surface fluxes are larger in CAM3 than ERA-40. Further downstream in the NAST, large positive heating bias appears in the diabatic heating that is mainly due to the positive bias in $P$; positive transient eddy heat flux bias (especially in the upper troposphere) occurs here too.

The temperature bias equation is studied by separating it into linear advection term, nonlinear advection term, transient term, and diabatic heating. The heat fluxes by transients are notable mainly at upper levels along the storm tracks. The Linear Group of terms is generally largest. When partitioned further, the linear advection terms (Linear Group) have some cancellation between vertical and horizontal heat fluxes along the storm tracks. Since the diabatic heating and precipitation in particular dominates along the ICZ, the vertical heat fluxes of the Linear Group are the main contributor there. We find that the nonlinear advection terms are small in the subtropics and higher latitudes except close to the Earth's surface. Small size of the Nonlinear Group is a necessary condition for using a linear model in a future study of the bias, but it is not sufficient since one must make a similar assessment of other equations in the linear model.

The strong bias of the diabatic heating in the downstream end of the NAST has a primary contribution from excess precipitation in CAM3. This raises the issue of whether that $P$ bias could be related to the Arctic surface bias of interest. We use lag and lead 1-point correlations of $P$ (at a point) and the Northern Hemisphere sea level pressure (SLP) in CAM3 data. We find that precipitation near the coast of France (where $P$ bias is large and along the CAM3 storm track) is correlated with higher SLP over western Russia and the Barents Sea. The model has a key positive SLP bias over the Barents Sea. Furthermore, correlation is clearly stronger for $P$ occurring before the SLP than after it, suggesting a possible cause and effect. Alternatively, there could be a third party common cause with a delayed response over the Barents Sea. Either way, higher $P$ on the downstream end of CAM3's NAST leads SLP bias over the Barents Sea.

Acknowledgments This research is supported by NSF ATM 0354545. ECMWF ERA-40 data used in this study/project were provided by ECMWF from the ECMWF data server. The authors gratefully acknowledge members of NCAR's Climate Modeling Section, Computer Software and Engineering Group, and Scientific Computing Division for their contributions to the development of CAM3. We thank Dr. Grant Branstator for suggesting that we study a temperature bias equation and for providing some useful comments on our results. We thank Dr. Kevin Trenberth for his suggestion to examine vertically integrated net heating and other helpful comments. We also want to thank two anonymous reviewers for their comments and suggestions.

Open Access This article is distributed under the terms of the Creative Commons Attribution Noncommercial License which permits any noncommercial use, distribution, and reproduction in 
any medium, provided the original author(s) and source are credited.

\section{References}

Boville BA, Rasch PJ, Hack JJ, McCaa JR (2006) Representation of clouds and precipitation processes in the community atmosphere model (CAM3). J Clim 19:2184-2198. doi:10.1175/JCLI3749.1

Branstator G (1990) Low-frequency patterns induced by stationary waves. J Atmos Sci 47:629-648. doi:10.1175/1520-0469(1990) 047<0629:LFPIBS > 2.0.CO;2

Briegleb BP, Bromwich DH (1998a) Polar radiation budgets of the NCAR CCM3. J Clim 11:1246-1269. doi:10.1175/1520-0442 (1998)011<1246:PRBOTN>2.0.CO;2

Briegleb BP, Bromwich DH (1998b) Polar climate simulation of the NCAR CCM3. J Clim 11:1270-1286. doi:10.1175/1520-0442 (1998)011<1270:PCSOTN >2.0.CO;2

Collins WD, Rasch PJ, Boville BA, Hack JJ, McCaa JR, Williamson DL, Kiehl JT, Briegleb B, Bitz C, Lin SJ, Zhang M, Dai Y (2004) Description of the NCAR community atmosphere model (CAM3). Tech. Rep. NCAR/TN-464 STR. National Center for Atmospheric Research, Boulder, p 226

Collins WD, Bitz CM, Blackmon ML, Bonan GB, Bretherton CS, Carton JA, Chang P, Doney SC, Hack JJ, Henderson TB, Kiehl JT, Large WG, Mckenna DS, Santer BD, Richard D, Smith RD (2006a) The community climate system model version 3 (CCSM3). J Clim 19:2122-2143. doi:10.1175/JCLI3761.1

Collins WD, Rasch PJ, Boville BA, Hack JJ, McCaa JR, Williamson DL, Briegleb BP, Bitz CM, Lin SJ, Zhang M (2006b) The formulation and atmospheric simulation of the community atmosphere model version 3 (CAM3). J Clim 19:2144-2161. doi:10.1175/JCLI3760.1

DeWeaver E, Bitz CM (2004) Maintenance of Arctic and Sub-Arctic atmospheric circulation in observations and CCSM simulations. In: Ninth Annual CCSM Workshop

DeWeaver E, Bitz CM (2006) Atmospheric circulation and its effect on Arctic sea ice in CCSM3 simulations at medium and high resolution. J Clim 19:2415-2432. doi:10.1175/JCLI3753.1

Dickinson R, Oleson K, Bonan G, Hoffman F, Thornton P, Vertenstein M, Yang Z-L, Zeng X (2006) The community land model and its climate statistics as a component of the community climate system model. J Clim 19:2302-2324. doi:10.1175/ JCLI3742.1

Grotjahn R (2008) Different data, different general circulations? A comparison of selected fields in NCEP/DOE AMIP-II and ECMWF ERA-40 reanalyses. Dyn Atmos Oceans 44:108-142. doi:10.1016/j.dynatmoce.2007.08.001

Grotjahn R, Osman M (2007) Remote weather associated with North Pacific subtropical sea-level high properties. Int $\mathrm{J}$ Climatol 27:587-602. doi:10.1002/joc.1423

Hack JJ, Kiehl JT, Hurrell JW (1998) The hydrologic and thermodynamic characteristics of the NCAR CCM3. J Clim 11:11791206. doi:10.1175/1520-0442(1998)011<1179:THATCO $>2.0$. $\mathrm{CO} ; 2$

Hack JJ, Caron JM, Danabasoglu G, Oleson K, Bitz CM (2006a) CCSM3-CAM3 climate simulation sensitivity to increased horizontal resolution. J Clim 19:2267-2289. doi:10.1175/ JCLI3764.1

Hack JJ, Caron JM, Yeager SG, Oleson KW, Holland MM, Truesdale JE, Rasch PJ (2006b) Simulation of the global hydrological cycle in the CCSM community atmosphere model version 3 (CAM3): mean features. J Clim 19:2199-2221. doi:10.1175/JCLI3755.1
Holton JR (1992) An introduction to dynamic meteorology. Academic Press, New York, p 511

Hoskins BJ, Hsu HH, James IN, Masutani M, Sardeshmukh PD, White GH (1989) Diagnostics of the global atmospheric circulation based on ECMWF analyses 1979-1989. World Meteorol Organ 326:18-19

Hurrell JW, Hack JJ, Phillips A, Caron J, Yin J (2006) The dynamical simulation of the community atmospheric model version 3 (CAM3). J Clim 19:2162-2183. doi:10.1175/JCLI3762.1

Kanamitsu M, Ebisuzaki W, Woollen J, Yang SK, Hnilo J, Fiorino M, Potter G (2002) NCEP-DOE AMIP-II reanalysis (R-2). Bull Am Meteorol Soc 83:1631-1643. doi:10.1175/BAMS-83-11-1631 (2002) $083<1631:$ NAR $>2.3 . C O ; 2$

Kiehl JT, Hack JJ, Bonan GB, Boville BA, Williamson DL, Rasch PJ (1998a) The national center for atmospheric research community climate model: CCM3. J Clim 11:1131-1149. doi:10.1175/ 1520-0442(1998)011<1131:TNCFAR $>2.0 . C O ; 2$

Kiehl JT, Hack JJ, Hurrell JW (1998b) The energy budget of the ncar community climate model: CCM3. J Clim 11:1151-1178. doi: 10.1175/1520-0442(1998)011<1151:TEBOTN > 2.0.CO;2

Lin SJ (2004) A "vertically Lagrangian" finite-volume dynamical core for global model. Mon Weather Rev 132:2293-2307. doi: 10.1175/1520-0493(2004)132<2293:AVLFDC >2.0.CO;2

Pan LL, Li T (2008) Interactions between the tropical ISO and midlatitude low-frequency flow. Clim Dyn 31:375-388. doi: $10.1007 / \mathrm{s} 00382-007-0272-7$

Pan LL, Jin FF, Watanabe M (2006) Dynamics of synoptic eddy and low-frequency flow (SELF) interaction. Part III: baroclinic model results. J Atmos Sci 63:1709-1725. doi:10.1175/ JAS3717.1

Rasch PJ, Stevens MJ, Ricciardulli L, Dai A, Negri A, Wood R, Boville BA, Eaton B, Hack JJ (2006) Characterization of tropical transient activity in the CAM3 atmospheric hydrologic cycle. J Clim 19:2222-2242. doi:10.1175/JCLI3752.1

Trenberth KE, Smith L (2009) The three dimensional structure of the atmospheric energy budget methodology and evaluation. Clim Dyn 32:1065-1079. doi:10.1007/s00382-008-0389-3

Uppala SM, Kållberg PW, Simmons AJ, Andrae U, da Costa Bechtold V, Fiorino M, Gibson JK, Haseler J, Hernandez A, Kelly GA, Li X, Onogi K, Saarinen S, Sokka N, Allan RP, Andersson E, Arpe K, Balmaseda MA, Beljaars ACM, van de Berg L, Bidlot J, Bormann N, Caires S, Chevallier F, Dethof A, Dragosavac M, Fisher M, Fuentes M, Hagemann S, Hólm E, Hoskins BJ, Isaksen L, Janssen PAEM, Jenne R, McNally AP, Mahfouf JF, Morcrette JJ, Rayner NA, Saunders RW, Simon P, Sterl A, Trenberth KE, Untch A, Vasiljevic D, Viterbo P, Woollen J (2005) The ERA-40 re-analysis. Q J R Meteorol Soc 131:2961-3012. doi:10.1256/ qj.04.176

Vavrus S, Waliser D (2008) An improved parameterization for simulating Arctic cloud amount in the CCSM3 climate model. J Clim 21:5673-5687. doi:10.1175/2008JCLI2299.1

Vincent D (1994) The South Pacific convergence zone (SPCZ): a review. Mon Weather Rev 122:1949-1970. doi:10.1175/15200493(1994)122<1949:TSPCZA > 2.0.CO;2

Williamson DL, Olson JG (1994) Climate simulations with a semiLagrangian version of the NCAR community climate model. Mon Weather Rev 122:1594-1610. doi:10.1175/1520-0493 (1994) 122<1594:CSWASL >2.0.CO;2

Willmott CJ, and Matsuura K (2000) Terrestrial air temperature and precipitation: monthly and annual climatologies. http://climate. geog.udel.edu/ climate (online)

Xie P, Arkin PA (1996) Analyses of global monthly precipitation using gauge observations, satellite estimates, and numerical model predictions. J Clim 9:840-858. doi:10.1175/1520-0442 (1996)009<0840:AOGMPU>2.0.CO;2 